\title{
English Pronunciation in Virginia
}

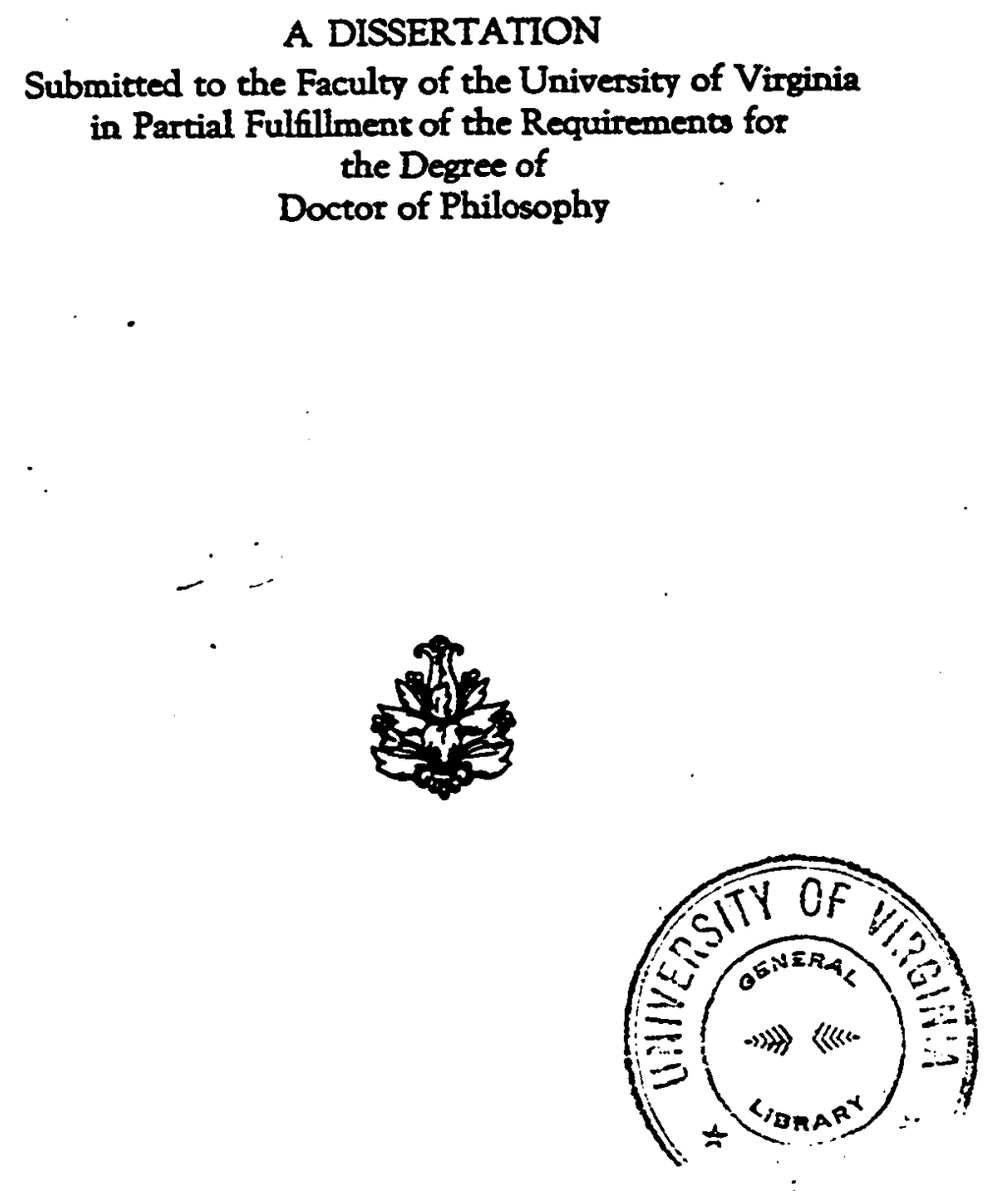

By

EDWIN FRANCIS SHEWMAKE Alumni Professor of English in Davidson College 


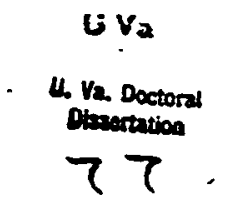

93975

\section{PREFACE}

This study of English pronunciation in Virginia was accepted in 1920 by the faculty of the University of Virginia as a doctoral dissertation. That part dealing with the dialectal pronunciation of ou and of $i$, was published in slightly modified form in Modern Language Notes, XL, 489 ff., for December, 1925. The editor of the Notes has kindly given permission ficr the use of the article here.

The author would thank all those who have in any way assisted or encouraged him in this undertaking. Especially does he wish to record his indebtedness to Professors John Calvin Metcalf and James Southall Wilson of the University of Virginia, Professor Percy W. Long of Harvard University, and Professor George Philip Krapp of Columbia University, all of whom have given valuable suggestions and advice. Thanks are also due to several editors and publishers for permission to use certain material for purposes. of quotation and summary. The titles of books and periodicals used in this way appear in the text, with specific references to volumes and pages.

Davidson, North Carolina.

E. F. S.

November, 1927. 


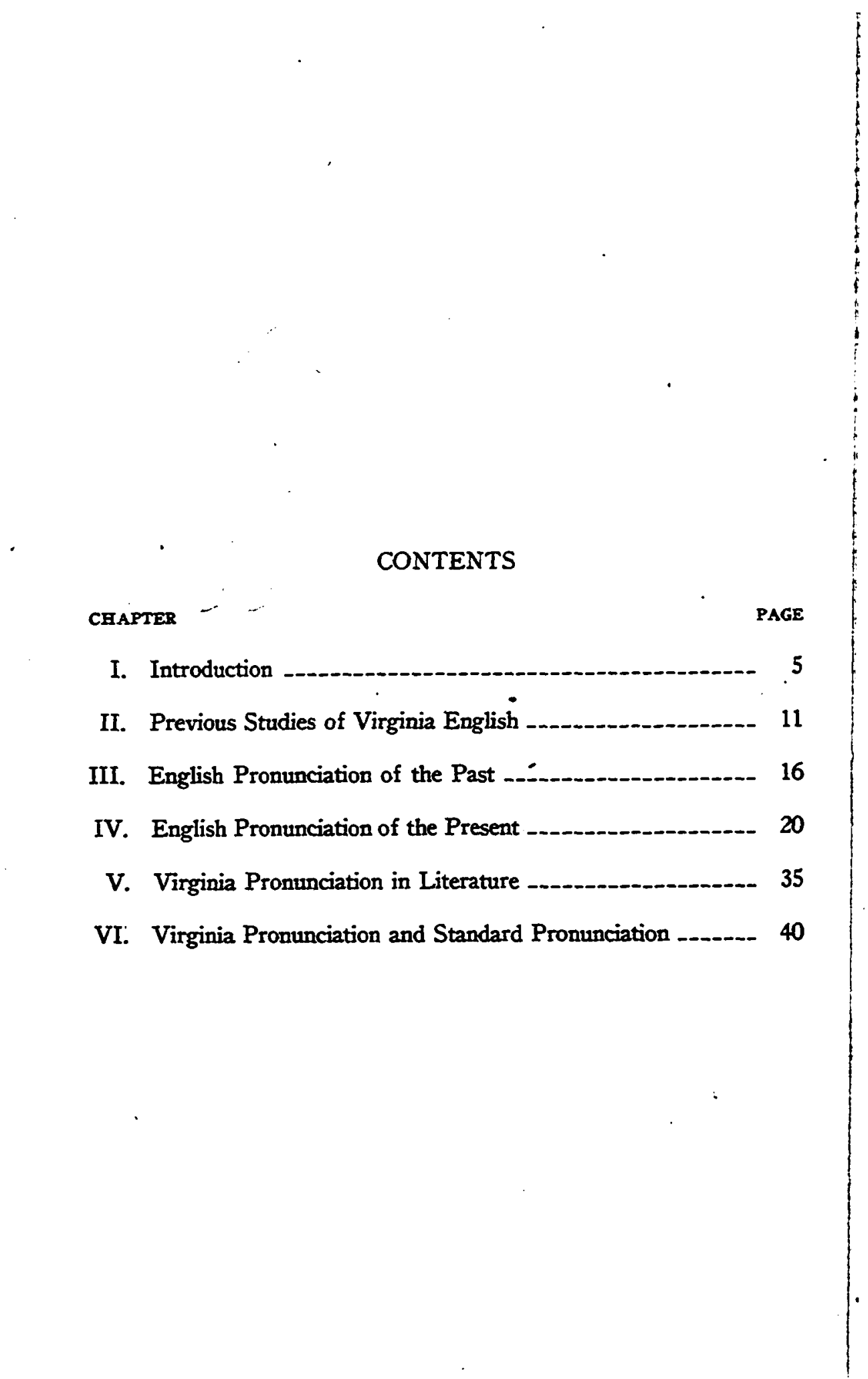




\section{KEY TO THE SYMBOLS USED IN THIS BOOK}

$A E-a$ as in cat.

AEAE— $a$ as in rat, but prolonged.

AH- $a$ as in father, or, when unstressed, $a$ as in artistic.

AH-I- $i$ as in fine.

AH-OO-Ou as in our.

$\mathrm{IU}, \mathrm{YU}-\mathrm{u}$ as in use.

$\mathrm{UH}-u$ as in hut, or, when unstressed, $u$ as in until.

$\mathrm{UH}-\mathrm{I}-i$ as pronounced in Virginia in ice.

$\mathrm{UH}-\mathrm{OO}-\mathrm{O}$ as pronounced in Virginia in out.

To be sounded accurately, the symbols $a h-i, a h-\infty, u h-i$, and $u h-00$ should be pronounced rapidly. 


\section{ENGLISH PRONUNCIATION IN VIRGINIA CHAPTER I.}

\section{INTRODUCTION}

Interest in the general subject of speech characteristics and peculiarities is so widespread that even those persons who care little for the study of language are at times attracted by some chance discovery of a difference between their own language customs and those of members of another community or section of the country. This attitude on the part of individuals who have neither a right nor a desire to be called language specialists. is of course traceable to the profoundly intimate relation that speech bears to human life. Man thinks of his language as a part of himself, and the feeling of joy aroused by the picture of a familiar scene is scarcely more intense than that which comes to one who hears his native accent in a distant clime. Each of these experiences flashes upan the "inward eye" a familiar image, and calls forth a multitude of close associations and tender memories.

But in America this general interest in language is too often superficial, if one may judge from the very small number of thorough studies of the speech characteristics of the different sections of the country that have been made. Though magazine articles have appeared from time to time, their authors have usually confined themselves to the explanation of a few salient characteristics, in a style noteworthy for its sprightliness and humor. One reason for the comparative neglect of this rich field of investigation may be that the points of difference between the speech habits of the three general geographical divisions of the United Statesthe North, the South, and the West-through rather numerous, are not very great in extent. It is well known that an American may travel in all parts of his country without experiencing serious linguistic inconvenience among the English-speaking population. The Englishman making a tour of his native land might be less fortunate. Professor O. F. Emerson says in speaking of the six modern dialects of Great Britain that "these differ so greatly, as spoken by the common people that a yeoman of one district might have difficulty in making himself understood in another." 1 Since the speech differences that do exist in America are not very marked in degree, it follows that they are not always clearly defined. It is therefore not easy to draw the line between the usage of one section and that of another.

It is clear, however, that the field of American English has three main divisions: the North, the South, and the West. For the purpose of a general discussion this classification would be sufficient; but since important differences arise within each of these divisions, it is well to make a more definite and restricted study. In accordance with this idea, the state of Virginia will give its name to the present investigation, though the field will actually be still more limited.

1 The History of the English Language, p. 99. 
This further limitation is made necessary by the fact that the speech habits of the people of the various parts of Virginia differ widely. Many dwellers in Southwestern Virginia and in the Shenandoah Valley are readily distinguished by their pronunciation, and to some extent by their vocabulary, from natives of the eastern counties of the state. Differences in history, combined with the separation maintained by mountain barriers, have resulted in so wide a divergence of speech habits that the eastern section, which is of course the older in point of settlement, must be chosen to represent the Virginia dialect. It will be convenient to use the term Virginia instead of Eastern Virginia, but the geographical distinction just made will be rigidly observed throughout the present study.

It was in the eastern part of the state, at Jamestown, in 1607, that the first permanent English settlement in America was made. Here was brought from England "the tongue that Shakespeare spake," and here that tongue continues to be spoken, with such modifications as time and circumstances have determined. Virginia English, then, has a longer unbroken history than that of any other state in the Union, though it has not, on that account, more archaisms of speech than some other parts of the country. Old pronunciations and old words, as well as old meanings of words still in use in other senses, are preserved longer in byways than on thoroughfares, and Eastern Virginia has long been the seat of a cultured civilization. Its people have therefore changed their language customs with the times. Here, however, are still heard many echoes of English usage of an earlier day; and when that has been said, one good reason for studying Virginia English has already been set forth.

Another reason for this investigation is the fact that Virginia English is fairly representative of Southern speech in general. Naturally, there are differences between the Virginia dialect and that of almost any other portion of the South that might be mentioned; but there is every reason to believe that Professor Emerson is right in thinking that this state and the Carolinas constitute the best field for the study of distinctive speech characteristics of the South ${ }^{1}$

Some of the peculiarities to be pointed out on the following pages are more properly associated with Virginia, perhaps, than with any other state; but such dialectal usages as, for example, the dropping of the sound of final $r$ in some cases and its vocalization in others are general tendencies in Southern speech rather than distinguishing marks of the dialect of one state or community.

Dialectal differences are often hard to trace, and it is always hazardous to say that a particular word or pronunciation is never heard in a given community. The best that can be done is to indicate in a rather broad fashion the area in which a given usage occurs. On the other hand, one must not be too general in the assignment of speech characteristics to certain localities. The city of Richmond is regarded as the speech center of the territory in which the Virginia dialect prevails,

1 The History of the English Langmage, p. 109. 
though dwellers in other cities of Eastern Virginia, as well as many rural folk of the same region, may speak this dialect in an equally representative way. Though Virginia speech is thus hedged in between the mountains and the sea, it is, in its broad outlines, characterized by most of the qualities that distinguish Southern English from Northern or Western.

Though it is not always possible to assign definite and entirely satisfactory reasons for the existence of a particular dialect or of the individual details of which it is composed, some of the influences that have contributed to the making of Virginia speech will be given brief consideration.

The antiquity of English civilization in this commonwealth has already been mentioned. Closely connected with that fact is the influence of the mother country on the colony for a long time after the settlement at Jamestown. Intercourse with England was fairly regular throughout the seventeenth century. New settlers were coming from time to time, and both commercial and literary relations existed. The speech of England in that century was also the speech of Virginia, with a few exceptions arising from the peculiar conditions of the new civilization.

The location of Virginia, as of the South as a whole, has perhaps exerted an influence in matters of language, and some of the differences between Southern pronunciation and that of colder climates may, it is believed, be accounted for in this way.

Has the presence of the negro had an appreciable effect on the speech of Virginians? This difficult question is too important to be dismissed without discussion. It has often been answered affirmatively by casual critics, but they have seldom, if ever, been able to point out definite and convincing examples to support their contention. To attribute a speech habit to negro influence because no other explanation suggests itself is unworthy and unjust and unscholarly; and to assign an unusual word or pronunciation to the negro merely because it happens to be found in his speech and also in that of the white man is illogical and absurd. It is better to approach the problem from the standpoint of the possibility and probability of negro influence in Virginia speech than to begin with a set of examples and to attempt to find for these an Afro-American source.

To see whether the negro can justly be held responsible for any considerable number of the speech characteristics of Virginians, one must ascertain first of all what his relations with the Anglo-Saxon element of the population have been. His social position has always been inferior. The white persons with whom he has at any time been on more or less familiar terms have been chiefly children, who in earlier days were fond of their old colored nurses, and who in the absence of companions of their own race sometimes made playmates of these nurses' children or grandchildren. But when the young Virginian reached manhood he naturally ceased to be influenced materially by negroes, in matters either of speech or of general conduct. Both the desire and the unconscious inclination to imitate the speech or behavior of negroes which he experi- 
enced and to which he doubtless yielded at times in childhood, lost their active power. The question now arises, Had early associations left their trace in the Virginian's speech? Doubtless they had unless counteracted by the force of the schools or of cultivated speakers of his own race. When it is remembered that some of the most characteristic negro pronunciations are seldom heard from the lips of any but the most illiterate white speakers, it seems unreasonable to suppose that many of the pronunciations learned from the negro by the white child clung permanently to the speech of the latter. The same may be said of violations of grammar. These are numerous in the speech of the illiterate negro; but they are a badge of illiteracy everywhere. Illiterate speech operates according to the same laws in all places. It results from imitation of the speech of the unlettered, or from imperfect imitation of reputable speech, and when once acquired it will cling to a speaker permanently unless there is some counterbalancing influence. In many cases, as has been suggested above, this influence is furnished by contact with educated speech.

It is readily granted that the white person who associates with negroes more than with members of his own race during his impressionable years will-speak as they do, but he will as quickly imitate the speech of any other illiterate persons.

But this is not all. Where did the negro acquire his speech characteristics? Certainly he gained them from the same source from which he got his language-the white man. That negroes are swayed by the speech influences at work about them is made ciear by the fact that those of the race who have lived long in other sections than the South have acquired ways of speaking in which scarcely a trace of Southern speech habits is preserved.

Language habits, though to some extent each person's speech is different from that of everyone else, are, in the main, group matters. In a large way the negro population of a state or section represents a somewhat homogeneous social group that is cut off from all other levels of society. The speech of a member of this group naturally reflects this homogeneity and comparative social isolation, even as do his home, his $d o g$, his superstitions, and other sure marks of his race.

When a negro speaks to a white man, he is giving back imperfectly a language that he learned from the other. His imperfections cannot more justly be attributed to him whom he is addressing than the:errors of a language student can be attributed to his teacher. In either case the only just censure would be that based on inadequate or imperfect instruction. That the Virginia negro speaks somewhat like the typical white speaker of the same state is not a disturbing fact. Language students would be puzzled if he did not, for speech habits depend upon association and imitation. Who has not known at least one impressionable person who went from his own section of the country for a short time and returned with peculiarities of pronunciation, enunciation, or accent at which his friends could not forbear to smile? If this experience is not uncommon, surely the Afro-American is entitled to a share of the speech 
habits of the white man of his own section as decidedly as he is entitled to a part of the sunshine in the community in which he dwells; and he can no more be prevented from enjoying one than the other.

But if the reasons given were left entirely out of account, it would still be inaccurate to say that the Virginia dialect is traceable in any marked way to negro influence, for the details that make it up are, in the main, either different from typical negro English or else are clearly derived from other sources. Furthermore, dwellers in other parts of America have speech characteristics in common with the Southern negro. Even New England does not escape, as can be seen by any observant reader of The Biglow Papers.

In trying to determine what Virginia English has been and is, it will be necessary to use several methods of approach. After a rapid survey of the more important studies bearing on the subject that have already been made, some of the noteworthy characteristics of the English language of the time of the Jamestown settlement will be considered. A language that lives at all is in a constantly changing condition. The usual threefold classification of the English tongue by periods known as Old Englist, Middle English, and Modern English is therefore not to be taken to mean that seventeenth-century English, for example, was identical with that which is called standard speech today. The language has perhaps changed in nothing more than in pronunciation since the great Elizabethan Age of English literature. Indeed, a twentieth-century American could not easily follow the reading of a paragraph rendered in the seventeenth-century manner. To understand, then, some of the changes wrought in the spoken word in the past three hundred years, and to provide an historical basis for some of the present-day peculiarities of Virginia pronunciation, it will be well to make a brief study of English pronunciation of the seventeenth century.

In examining the characteristics of Virginia English of the present time, it will not be sufficient to say that a certain peculiarity of speech is found in Virginia, for the extent to which a given usage prevails and the rank it occupies in Virginia English are matters of a good deal of importance. Though it will be necessary to make a good many classifications and distinctions, the results cannot in every case be conclusive, nor can the stady be called complete; but it is believed that an investigation of the speech, and especially of the pronunciation, of Virginians in the light of so-called standard American English is the only method by which the Virginia dialect can be explained with even an approach to accuracy and fullness.

Peculiarities will be assigned, whenever possible, to their proper levels. These levels will be determined by the fact that there are in Virginia, as elsewhere, two general classes of speakers, the educated and the uneducated. Each of these classes has, however, language habits that vary with the constantly shifting conditions of speech. This variation suggests another classification of speech as formal and informal. Furthermore, there are many degrees of formality and of informality, of care and of carelessness; and so it will be necessary to distinguish 
between peculiarities that merely suggest informality or carelessness on the part of an educated speaker and those which mark the speech of the uneducated.

It is not difficult to distinguish between the formal and the informal speech of the uneducated, for members of that class apparently believe that the use of polysyllables adds effectiveness to their remarks; but simpler words meet most of the illiterate speaker's needs in familiar speech.

Literary English is naturally subject to fewer differences of usage than is spoken English. There are sometimes divergences of vocabulary, spelling, and syntax between English and American books; and a few variations in matters of usage may be noted when the work of a Southern writer is compared with that of a Northerner. These differences are, for the most part, aside from the purpose of the present study.

The level of usage known as cultivated spoken English is by no means the same in the different parts of the United States. If it were, the present investigation would be a vain undertaking.

On a lower level than literary English and the spoken English of the cultivated is popular English, or the speech of the masses. It is of course colloquial, not literary, though it is sometimes reduced to writing. The illiterate speaker, though he may be a worthy citizen in many ways, respects not, indeed knows not, the laws of the grammarian. The language of a Virginian of this class is in general like that of illiterate speakers in other parts of the country; but almost any paragraph of this kind of speech, if recorded phonetically, will reveal peculiarities that indicate its Southern, if not its Virginia, origin.

One other method of approaching the Virginia dialect remains to be mentioned. General attention was drawn to the language characteristics of the North, the South, and the West during the latter part of the nineteenth century by the rise and steady growth in popularity of dialect writing. Authors of Southern stories have availed themselves of this powerful aid to realistic writing, and the Virginia character has appeared with his speech in its native dress in works by several authors who know Virginia customs so well that their attempts to represent in writing some of the dialectal words and pronunciations of the state are entitled to close study. It will be worth while to compare the Virginia dialect as it is observed in real life with some of the versions of it that have appeared in books. Abundant material for such a comparison is provided in this volume. 
Encisst Pronunciation in Virginia

CHAPTER II.

\section{PREVIOUS STUDIES OF VIRGINIA ENGLISH}

The extent to which the Virginia dialect has been discussed in works previously published is by no means great enough to discourage further investigation. It is believed that the late Dr. B. W. Green was the only Virginian who has ever attempted a very detailed study of the speech of the Tidewater section of the state; but since he did not fully classify and analyze the many words and pronunciations recorded in his Word-Book of Virginia Folk-Specch, his work is a source of assistance and inspiration rather than of despair to other laborers in the same field.

The purpose of the present chapter is to set forth the principal conclusions that have been reached by writers who have published the results of their study of Virginia English.

A very scholarly and valuable attempt has been made to record the peculiarities of pronunciation of a representative section of Eastern Virginia by Sylvester Primer in an article on "The Pronunciation of Fredericksiburg. Virginia," which appeared in the Publications of the Modern Language Association of America. ${ }^{1}$ The author takes seventeenth-century English pronunciation as the foundation for his study. and he shows by transcriptions the state of English pronunciation when Virginia was first permanently settled by the Anglo-Saxon race.

Primer's discussion of the present-day characteristics of Fredericksburg or. we may say, Virginia, pronunciation is the most detailed that has yet been written. The main points to which he calls attention are these:

1. The use of the Italian or broad $a$.

2. The two distinct pronunciations of words like calm, palm, psalm, and half. According to one of these, palm, for example, rimes with the Southern pronunciation of harm, which is hahm; according to the other it rimes with lamb.

3. Lack of uniformity in pronouncing words like ask, demand, and pass. Primer heard, or thought he heard, the $a$ of this group pronounced like the $o$ of important and mortal.

4. Distinction between the pronunciation of ant and that of aunt.

5. Three pronunciations of $a$ in words of the type of gaunt, haunt, and jaunt. These three may be indicated roughly by gaunt, gahnt, gaent; haunt, halint, haent; and jaunt, jahnt, jaent.

6. Thar and whar for there and where. The author of the article is not sure whether these pronunciations are " $a$ reflex of the older pronunciation or a result of the influence of the negro element."

7. The pronunciation of stairs and bears as if they were spelled stors and bars and, conversely, the pronunciation of stars as if it were written stairs.

1 Vol. 5, pp. 198f. Used here by permission. 
8. A tendency to pronounce such words as appear, bear, dear, deer, ear, gear, hair, hear, here, pair, pare, stare, spear, tare, almost if not exactly as if they rimed with the Southern pronunciations of gayer, layer, and payer (gay-uh, lay-uh, pay-uh).

9. The same sound of $u$ in put as in but, hut, and rut, and something approaching that sound in could, would, and should. In attempting to describe this peculiarity Primer mentions book, cook, good, room, shook, spoon, and took.

10. A dialectal pronunciation of ou in some words. Though this characteristic of Virginia speech seems to have interested Primer greatly, it does not appear that he grasped the real basis of distinction between what may be termed the Virginia sound of on in house and the sound of the same diphthong in houses. He probably recognized, however, the existence of two classes of ou words, for he mentions about, house, out, and south to illustrate one sound of the diphthong, and cow and town to illustrate another. He also distinguishes between round, sound, and bout, doubt. kyart.

11. The use of a palatal glide after $g$ and $k$, as in gyarden and

12. The substitution of the sound of $n$ for that of $n g$ in final ing.

13. The following departures from standard pronunciation: $g$ it for get, po for poor, year for ear (the $r$ is vocalized and has the $u h$ sound; that is, the sound of $u$ as in hut), yisterday for yesterday, bazend for bond, and pazend for pond; but the author states that bond and pond are also heard.

"Survivals in American Educated Speech" is the title of an interesting article in the Bookman." The author, S. D. McCormick, says that "survivals in American educated speech are more strikingly illustrated in Virginia and Massachusetts than in other sections of the Union." He adds that "Richmond and Boston-long the recognized centers of culture of the two antagonistic civilizations on the Western Continent-are each characterized by somewhat radical departures from accepted canons where English is spoken. In other words, each is the repository and exponent of curious anomalies and of seventeenth and eighteenth-century fads-survivals which mark educated speech."

McCormick sees in the Virginia dialect a twofold character.: He therefore separates his study of this division of the subject into two parts, the first of which deals with the glide or vanishing sound of $y$, the second with the so-called Cavalier $a$.

In a series of clever paragraphs the author succeeds in using a large number of words in which the $y$ sound appears in the speech of some Virginians. Among these are Kearter, kear, kyard, gearnitures, gearland, kearnation, keartoon, kearpets, gearden. gearb, gearment, keargo, skey, keindness, kyites, gyide, gyard, gyile, and gyise.

1 Vol. 11, pp. 446f. Uaed bere by permispion. 
The author points out that these peculiar pronunciations did not originate in Virginia, but that they were "the prevailing literary vogue in England during the last quarter of the eighteenth century and the first quarter of the nineteenth century." To the trath of this assertion he calls three early lexicographers, Sheridan, Walker, and Smart, to witness.

Continuing, the writer says: "Contrary to the ustal custom of dialectal speech, these peculiarities have never entered into folk-speech." He attributes their survival in educated speech to the fact that "Virginians, owing to climatic or racial influence or to early culture or to some congenital trait, are endowed with a most musical intonation, so that this dialect when once acquired is rarely abandoned."

The second part of "Survivals in American Educated Speech" deals with the so-called broad or Italian or Cavalier a sound, which may be represented by $a h$, and which occurs in dialectal English in a good many words in which it is not heard in the pronunciation of Americans in general. McCormick regards this peculiarity as "the most distinguishing feature of the Virginia dialect;" but the history of this sound, its present status, and its probable future are so nearly those of the $y$ sound already mentioned that nothing further will be said of it at this point.

A study of Northern-or Western-and Southern speech differences is found in the Contributors' Club of the Atlantic Monthly' in an article entitled "They Spake in Divers Tongues." The author, though no name is given, is a woman, and evidently a Virginian, for in speaking of the pronunciation of gyarbage, or geearbage as she represents it, she says that "in Virginia we argue for its correctness." The following list contains some of the more important differences between Northern or Western and Southern usage as the author of the article observed them in her new surroundings:

Nortaern OR Western Forms guess (for think or suppose)

you people, you folks

lug

pail

husking sweet corn

spider

howse, abowt

Toosday, dooty, noo
SOUTHERN Foracs reckon (but never reckoned or was reckoning in this sense) you all (always plural) tote bucket shucking roastin' ears skillet house, about Tuesday, duty, new

Other Northern or Western peculiarities mentioned in the same article are weat for wheat, wen for when, you don't want to for you mustn't, hadn't ouglut, allus for alzays, I presume likely, I want you should, and calculate for think. This significant statement also occurs: "The longer $i$-heard also in some Southern states and, much prolonged. throughout Appalachian America-sounds pretty, and has, I believe, such authority as dictionaries can give" 
Professor C. Alphonso Smith, who contributed the chapter on "Dialect Writers" to the Cambridge History of American Literature," gives these seven classes of Southern speech peculiarities, every one of which is found in Virginia:

1. The use of like for as if as a subordinating conjunction.

2. The use of 'low and allow for think or say.

3. The sound of iu or yu, not that of $\infty$, in words like tune, nezws, and $d u t y$. "This pronunciation," says Professor Smith, "like the retention of broad $a$, can hardly be called dialectal; but it is almost a shibboleth of the Southerner to the manner born, and helps to differentiate him from the Westerner and Northerner."

4. The glide or vanishing $y$ sound in gyarden, cyards, Cyarter, Gyorfield, and similar words.

5. The use of broad $a(a h)$ in words of the type of dance, task, and past.

6. The omission of the $r$ sound in such words as more, store, floor, fow, door; and the vocalization of $r$ in these and similar words when ix is not slighted altogether. The author of the article represents the first of these peculiarities as characteristic of negro speech; the second he attributes to the white element of the population.

7. You all (always plural) for you people, you boys, you girls, and like expressions.

Among larger works dealing wholly or in part with Virginia speech, first place must be given to the Word-Book of Virginia Folk-Speech mentioned at the beginning of this chapter. This volume, though not meeting fully the demands of modern scholarship, is nevertheless valuable for its large number of Virginia words, pronunciations, and familiar sayings. The author lived in the Tidewater region, in Warwick County, and he knew the characteristics of the living speech of that locality better, perhaps, than any one else who has written on the subject. Though many of Green's expressions and pronunciations are not peculiar to Virginia, or even to the Southern States in general, it is doubtless true that they all have a place in Virginia speech.

In Bartlett's Dictionary of Americanisms (second edition, 1859) are found a few comments on Southern pronunciation:

"The chief peculiarity of the Southern and Western people is the giving of a broader oound than is proper to certain vowels; as whar for where, thar for there, bar for bear. Ee and here are both pronoenced like year; house, aboxt, ete, bave a pronunciation approachine and hoose, aboot, etc; and the final $r$ is omitted, as yow, do, for your, door, etc"

In a list of dialectal expressions said to be heard in the different sections of the country, Bartlett identifies these with Southern speech: drap for drop, the pronunciation of idea with the accent on the first syllable, grwine for going, hath for hecorth, shet for shut, skeart for scored, torectly for directly, year for ear, the pronunciation of only with short 0 , yere for here, and smaart for smart. It is supposed that Bartlett means to indicate the sound of short $a(a e)$ when he writes ae in smaart.

\footnotetext{
1 Vol. 2, pp. 347ff. Used here by permission of G. P. Putnam's Sons, publishers.
} 


\section{Noah Webster says in his "Dissertations on the English Language": :I \\ "Some of the Southern people, particularly in Virginia, almost omit} the sound of $r$ as in zucure, there." Webster also mentions what he calls "the very modern pronunciation of kind, sky, guide, etc., in which we hear the short $e$ before $i . "$ He states that this pronunciation belongs to the speech of fashionable people both in England and in America, but he himself does not commend it.

With the foregoing review of the leading previous studies of Virginia English and Southern English as a background, a new study of the subject will be begun in the next chapter.

1 Qroted in Ellis's Early English Promunciation, p. 1066. 


\section{CHAPTER III.}

\section{ENGLISH PRONUNCIATION OF THE PAST}

A long time has passed since "the morning star of song" lived and wrote, and yet the average reader has comparatively little difficulty in getting the sense of the lines of the Canterbury Tales. But if he hears these same lines read aloud with proper attention to the rules of fourteenth-century pronunciation, many of the sounds that fall upon his ears are like those of a strange tongue.

Chaucer died more than five hundred years ago, and the English language has changed greatly in pronunciation since that poet's day. It will readily be understood, then, that the pronunciation of seventeenthcentury England, though a good deal nearer that of our own time, has characteristics in strong contrast with those of modern standard pronunciation. It follows also that America, settled as it was by the English in the seventeenth century, preserves some of these historically interesting pronunciations in its dialects. This is particularly true of Virginia and Massachusetts, where the earliest permanent English settlements were made.

E. A. Abbott, who explains so many interesting peculiarities of Elizabethan English in $A$ Shakespearian Grammar, has very little to say in that volume about early English pronunciation. The three main points to which he calls attention are that the Elizabethans probably spoke more rapidly than is the custom today, that they used a good many contractions, and that accents were shifted from one syllable to another at times in "the same words in the same author." The last named tendency Abbott traces to the fact that "the foreign influence was contending with varying success against the native rules of English pronunciation."

These three characteristics, though not without importance and interest for readers, explain so few of the qualities and tendencies of Virginia speech of the present day that a more detailed study of seventeenth-century pronunciation must be made. The materials for such an investigation are furnished in abundance in Ellis's Early English Pronunciation, which contains a good many concrete examples of the pronunciation of the period to which Virginia English historically belongs.

The words in the following list are pronnunced according to the authority of Ellis, who includes these and others in his work (pp. 1001ff.) Instead of a phonetic alphabet, the rather loose but more easily understood method of indicating pronunciation in the way used by dialect writers has been adopted here to show in a general manner the pronunciation of typical words and classes of words three centuries ago. The single exceptions to this method are the use of ae to indicate the so-called short sound of $a$, as in hat, and of asae to indicate the same sound prolonged. As all the words discussed below are familiar to everyone, it will be unnecessary to give accents. In the absence of com-

1 Abbota: A Shakespearion Cranimar, third edition, p. 11. 
ment, the reader may assume that the accent in a given word fell on the same syllable in the earlier period as that on which it falls today.

ABIDE (aebide). This is one of several words in which initial $a$ was sounded much more clearly than it is at the present time.

ABLE (aeaeble). The initial sound here was the same as that of abide, but prolonged. Ellis says of this sound that it was going out of use in Dryden's day (1631-1700), but that Dryden himself "most probably retained his youthful habit (acas) to the last.

ABOUT (aebout). See abide.

ACORN (aeakern). See able.

ADVENTURE. The significant fact about the pronunciation of this word in the seventeenth century is that the final syllable was sounded as if spelled ter. Thus an historical basis is afforded for several dialectal pronunciations of today.

AFFAIRS (affayers). Modern American pronunciation approaches that of the earlier period, but in Virginia the ae or acac sound is heard in the second syllable.

ANOINT (an'int). $O i$ in this word and many others was not pronounced as it is today. The prevailing scund was that of $i$ as in pint. the so-called long $i$ sound. Some of these early pronunciations are heard still in illiterate speech.

BAPTISM (baptism). A general tendency to substitute voiced or sonant $b$ for voiceless $p$ is observed in the speech of the uneducated at the present time.

BAR (baer). This pronunciation is perhaps obsolete. but there are Virginians still living who have often heard are called acr, or, rather, $a e-u h$.

BARE (baezer, bayer). The sound is common in Virginia, but the ay sound or the one that approaches it appears to be used rather widely in America.

BARGAIN (baergen). See bar.

BARGE (baeaerge). See bar.

BARROW (baerro'). The $o$ sound is often slighted in present usage in words ending in unaccented ow.

BASIN (baes'n, bas'n). The second pronunciation now prevails. The other illustrates again the difference between seventeenth-century a and that of the present time.

BEAR. As a verb the word was pronounced bayer, as it is by many speakers now; as a noun it was sometimes bayer and sometimes baceer; but bae-uh or boeve-uh is heard in Virginia for both verb and noun. Perhaps no speaker anywhere makes a distinction between the pronunciation of the word when used as one part of speech and when used as another. 
BEARD (bayerd).

BEAST (bayst).

BLAST (blaeaest). This pronunciation, shurned by some speakers today as inelegant. is now, as it was in the earlier period, the general pronunciation in America.

BROIL (brile). See anoint.

CALF (cauf). Many words in which some speakers give the sound of $a$ heard in father, others the sound of the vowel in hat, and still others the intermediate sound, were pronounced in the seventeenth century with the sound of $a$ in call and fall.

CALM (caelm). Two peculiarities are to be noted here: the fact that the vowel sound was that of short $a$, and the fact that the $l$ was pronounced. Some speakers of the older generation in Virginia still preserve the first of these characteristics, which apparently belongs also to the lower levels of present-day English usage; but the $l$ is perhaps never sounded in modern speech.

CARD (kaeaerd). See barge.

CAST (kaeaest). See blast.

CHAIR (chaer). This pronunciation of the vowel is general in Virginia.

COIN (kine). See anoint.

EMBALM (embaelm). See calm.

ENHANCE (enhaunce). See calf.

FAIR (fayer). This is often heard in America today, but in Virginia faeae-uh or fae-uh seems to prevail.

FARE (faeaer). Virginians who pronounce the preceding word facae-uh or fae-uh pronounce this one in the same way.

FATHER (faeaether). This pronunciation was heard a few years ago in Warwick County, Virginia, and is doubtless the current pronunciation with many speakers in Tidewater Virginia who have acquired their speech habits almost entirely through imitation of the language habits of others. A pronunciation may survive in the same way that a popular ballad lives from generation to generation.

GET (git). This historical pronunciation should be pondered by all who are tempted to assign every slipshod pronunciation to negro influence.

GLANCE (glaunce). See calf.

GRANT (graeaent). See blast.

HAIR (hayer). See foir and fare.

HAUNT (haent). This is the illiterate pronunciation of the word today. 
HIM and HIS ('im and 'is). These weak forms are still heard when no stress falls on the words.

IT HAS ('taes).

IT IS ('tis).

JAUNT (jaent). See haunt.

LASTLY (laesly). Dropping consonants characterizes careless speech today.

LAUGH (laef). See blast.

LAUGHTER (lawter).

MARSH (maesh). See bar, but note that here the $r$ drops out altogether. Compare the modem careless pronunciation paecel for parcel.

NATURE (nater). See adventure.

OUT and OWL. The diphthongs in these words were, it seems, often pronounced alike, and they are still pronounced alike in standard American English, but not in the Virginia dialect. The fact that one diphthong is ou and the other is ow does not fully explain the distinction. See the discussion of the Virginia on (pp. 23-24).

PALM (paum). See calf and calm. Note the inconsistency of saying caelm and paum.

PASS (paes). See blast.

PERCEIVE (persave). This is no longer heard in ordinary speech.

PICTURE (picter). See adventure.

PSALM (saum). See palm.

SUIT (syut or siut and shoot). Syut or siut is academic in Virginia today; shoot is not heard. Compare the modern pronunciation of $s$ in sure and sugar.

In view of the rather careless habits of pronunciation of even cultivated speakers of three hundred years ago, it is unnecessary to set forth proof of the existence of a good many slipshod and non-standard forms in the usage of uneducated Virginians of the seventeenth and eighteenth centuries. But this discussion of Virginia English of the past will be concluded with the following significant quotation from William Wirt Henry's Patrick Honry: Life, Correspondence, and Speeches (Vol. 1, p. 28) : 1

1 Qwoted by permiscion of the publishers, Charles Scriboer's Sons.

"Mr. Jefferson told Daniel Webster that his [Patrick Henry's] pronunciation was vulgar and vicious; and Governor Page related that he once heard him say: 'Naiteral parts is better than all the larnin' upon yearth.' This vicious pronunciation and bad grammar were evidently used to point some exhibition of humor, of which Mr. Henry was fond, as he was undoubtedly a good grammarian. What is called valgar and vicious pronunciation by Mr. Jefferson was doubtless the country mode of pronouncing certain words, which struck the ear of the polished Jefferson unpleasantly. These peculiarities of pronunciation were not confined to Mr. Henry, however. We are told by Judge Roane that the accomplished Edmund Pendleton was in the habit of saying scaicely for scarcely, and the no less scholarly John Taylor, of Caroline, of saying bure for bor." 
CHAPTER IV.

\section{VIRGINIA PRONUNCIATION OF THE PRESENT}

Virginians are distinguished from other Americans less easily by their vocabulary and syntax than by their pronunciation. A speaker may talk for an hour without using many words or constructions that are not standard; but his peculiarities of pronunciation will reveal themselves in almost every sentence that he utters.

A dialectal sound may be interesting because of its rather great departure from the standard to which speakers are accustomed; or it may derive its importance from the fact that it suggests an interesting detail of language history; or it may be deemed worthy of mention by reason of its prevalence in the community, the state, or the section to which it belongs. Each of the characteristics of Virginia pronunciation to be mentioned in this chapter can be traced to one or more of these three sources of interest.

One of the most distinctive peculiarities of Virginia pronunciation is the insertion of a g!ide or vanishing $y$ sound between $g$ and $a$ in words like garden and garnicnt, between $c$ or $k$ and $a$ in such words as card and carpet, and after $c$ or $k$ in words of the type of sky and kind.

There are at least two reasons for the clearness with which this archaism-for such it is-impresses itself upon the observer of speech characteristics. In the first place, the departure from standard pronunciation represented in gyarden, cyarpet, kyind, and other words of the same class is sufficiently great to be easily noticed. The average speaker is thoroughly accustomed to failure on the part of his associates to pronounce certain letters used in spelling words, but the practice of supplying a sound for which there is no letter is by no means so common in English speech. Another reason for the distinctiveness of this peculiarity is the limited use that it enjoys. This limitation is less geographical than social. for the vanishing $y$ is heard in more than one Southern state. though, generally speaking, not among all classes of society. The average Virginian employs the sound not at all, though he hears it with sufficient frequency to be aware of its existence.

By whom, then, is this sound used? It is heard chiefly in the speech of men and women of the older generation belonging to some of the old, highly cultured families. Occasionally the younger members of these families have learned this pronunciation from their parents and may continue to use it throughout their lives. But many a highly cultivated Virginian pronounces words of the garden variety in the standard American way; and. on the other hand, some illiterate speakers have picked up this speech habit from those to the manner born.

It is easy to see that the vanishing $y$ is indeed vanishing from Virginia speech; but before any reader or hearer condemns this peculiarity and looks upon its use as the result of affectation or conceit, let him remember that it was formerly sanctioned by more than one English 
lexicographer. John Walker had this to say about it under the word garden: 1

"When the $a$ in this and similar words is preceded by $g$ or $k$, polite speakers interpose a sound like the consonant $y$ which coalesces with both. and gives a mellowness to the sound; thus a garden pronounced in this manner is nearly similar to the two words egg and yorden united into eggyarden, and a grasd is almost like eggyord"

In connection with guard Walker explains the sound again and adds that it is not a fanciful peculiarity, but a pronunciation arising from euphony and the analogy of the language. Again, in his essay on "Principles of English Pronunciation" the same author declares that such pronunciations as gyarden, kyind, and others of the same type are correct; and he criticizes Nares for saying in his English Ortinoepy that "kyind for kind is a monster of pronunciation, heard only on our stage." Walker also gives his sanction to the $y$ sound in gird and similar words.

Richard Grant White, in his Every-Day English (p. 53) cannot fully agree with a statement by Professor Whitney that this glide or $y$ sound is "one-of the latest downward steps in English orthoëpy," for, as White asserts, and as the evidence abundantly proves, this pronunciation had been in use, in Whitney's day, for a good many years. The most tolerant, and doubtless the most sensible, attitude toward this sound is that of Richard Grant White, who regarded it as "a little evanescent grace of speech which is beginning to pass away." "The wisdom of our ancestors" is indeed in this speech habit, and that fact gives additional interest to what is in itself a very interesting peculiarity.

The present rank of the $y$ sound under discussion is indicated briefly in the New International Dictionary as archaic or dialectal, though it is further characterized in that work as "formerly in vogue, and still heard in some parts of England and the United States." Something remains to be said of its employment at the present time in Virginia. The prevalence of this pronunciation may be tested by the use of the type words, carpet, garden, kind, guide, girl. Of those speakers who make use of the sound at all, some probably insert the glide vowel in all these words with regularity; but others omit the $y$ in pronouncing one or more of the five. The two in connection with which the tendency to omit $y$ seems greatest are kind and girl. Guide would perhaps come next in order, leaving carpet and garden as the representatives of the two types in which the dialectal pronunciation is more regularly heard. : It also appears to be true that some speakers insert the sound under discussion in a given word at one time and omit it at another time from the same word. A Virginia woman states that on a certain occasion she happened to speak of Mr. Carter instead of Mr. Cyarter and was promptly "corrected" by her father, who explained that a carter is one who drives a cart, whereas Cyarter is a gentleman's name!

Some speakers interpose the glide vowel in a more emphatic way than do others. When given its full value the glide vowel has almost the same sound as $y$ in yes; but when pronounced more lightly it has

1. The edition of Waller consolted is that of 1823. 
somewhat the sound of $i$ in pin. This latter sound seems to have been recorded only in modern times, and there is little to be gained by an attempt to differentiate the two. They are so nearly alike that it is not improbable that they have existed side by side since this glide vowel was first introduced into English.

All inconsistencies in usage connected with the vanishing $y$ sound are easily explained. The sound is employed by comparatively few speakers and it appears to be steadily passing out of the language. There is, therefore, not the same tendency toward uniformity in this that there is in a standard sound. It cannot stem the analogical current in favor of the pronunciation of garden and similar words without the glide vowel. It is as if the morale of this archaism were weakened by the fact that the sound is engaged in a losing fight.

There is so much diversity of opinion and of practice in regard to the pronunciation of words like path and dance that the custom or customs prevailing in Virginia may well claim attention in this discussion. There can be no doubt that the great majority of Virginians pronounce these words with the sound that $a$ has in man, but the pronunciation with the so-called broest or Italian or Cavalier $a$ and also that which includes what is known as intermediate $a$ are both heard at times. The broad $a$, which is the sound of the three that is associated with the Virginia dialect, has an interesting history; it is heard in parts of England, and is found in other parts of America besides Virginia. Richard Grant White praised this as the most profitable sound for practice by those wishing to develop the organs of speech, and he also regarded it as the best sound to employ in the group of words represented by dance and path. We have, then, a traditional or historical sound of this letter which may be represented by $a h$; the so-called short sound, like $a$ in man; and an intermediate sound, given and sanctioned by the leading American dictionaries, as a compromise between the other two. The habit of most speakers is to rely upon the dictionary as the final arbiter in matters of orthoepy. This practice naturally increases the favor in which the intermediate sound is held; and many a speaker with a linguistic conscience but without the courage of his convictions continues to side with the majority and give these words the sound of $a$ in man, having all the time the feeling that he is wrong.

But since usage, not authority, is the final test of the correctness or appropriateness of a language custom, and since the majority of educated speakers use the short sound of $a$ in these words, it follows that for Virginians, as for other Americans, this is an entirely proper pronunciation. Anyone who prefers either of the other two sounds is free to adopt it. All three pronunciations, then, are good; but in this as in other cases of divided use, a given speaker will wish to be guided to some extent by the usage of the community or class of speakers of which he forms a part. ${ }^{1}$

1 A vers intereating discusion of these three soends in comparison and contrast with one anotber is given in Profeseor Krapp's The Pronumiation of Standerd English in Americe, pp 63, 64. See also the same anthor's Hodern English, pD. 131-134. 
Though the vanishing $y$ sound of gyarden and the broad sound of $a$ in dance (dahnce) are possibly regarded by persons outside that commonwealth as most characteristic of Virginia pronunciation, they cannot be given that high rank by any observant resident of the state. First place from the standpoint of dialectal pronunciation must be accorded two sounds of which scarcely any mention is made in the modern dictionaries and guides to pronunciation; and yet they are such commonplaces of Virginia speech that those who use them are in the majority of instances not at all conscious of their singularity. Cyarter and gyarden are so rarely heard as almost always to be noticeable; and dahnce and pahth are hardly less so; but the Virginia pronunciation of the two classes of words now to be discussed is rooted firmly in the speech habits of the majority of people of all classes, and perhaps no effort is ever made, unless by an outsider, to normalize them on the basis of national usage. These two interesting sounds may be represented by the type words out and like.

According to modern dictionaries, ou in about, house, and out is pronounced like the ou or ow of crowd, how, and loud.'

But reasunably careful attention to the pronunciation of these six words by a native of that part of Virginia lying east of the Blue Ridge Mountains-known as Eastern Virginia and embracing the Piedmont and Tidewater sections-will reveal a marked difference between the ou sound of the first group (about, house, out) and that of the second (crowed, how, loud).

The so-called standard pronunciation of diphthongal ou is approximately that of $a$ as in father plus that of 00 as in pool or possibly that of $o o$ as in foot: but the dialectal pronunciation heard in Eastern Virginia is approximately that of $u$ as in hut plus the same sound used in standard pronunciation for the second part of the diphthong. Standard ou may be represented by (au) or (ah-oo) and dialectal ou by $(u h-\infty$. The standard is perhaps more theoretical than actual, for there is room for a number of slightly different sounds ranging between that of $a$ as in father and that of $u$ as in hut as the first element of the diphthong; but for convenience and clearness in making the distinction between Eastern Virginia usage and that of the United States as a whole, only the two sounds here called, respectively, standard ou and dialectal ou will be included in this discussion.

According to their pronumciation of such words as about, house, out, crowed, how, and loud, American speakers of English may be divided into three classes. Those of the first class - which is by far the largestuniformly employ in all these words the sound called standard. Members of the second class-which is the smallest-with equal regularity substitute dialectal ou for standard ou in the words given. The third

1 In present-das English, the spelling is uswally, if not always, ow when a voiceless consonant immedintely follows in the same syllable (ont), and is usually ow when the sound thrs represented is at the end of a syllable (how, bot note thow 28 an exception); but when 2 voiced consonant immediateiy follows the diphthoos in the same syliable, the spelling is sometimes on (loud) and sometimes ow (crowd). 
and, from the standpoint of typical Eastern Virginia speech. the most interesting class includes those who pronounce about, house, and out with dialectal ou, and crowd, how, and loud with standard ou.

This seeming inconsistency invites study. Since speech is a social custom, and since speakers of a given region are not likely to be unaccountably inconsistent in their pronunciation of a given letter or diphthong, it is well to ask whether some principle can be discovered which members of class three follow. It is strange that this survival of older usage has not earlier yielded its secret; and yet not even an attempt to explain such peculiarities as dialectal about, house, and out beside standard crowed, how, and loud, and dialectal house beside standard houses can be found. ${ }^{1}$

Careful and prolonged observation and the application of tests to a number of Eastern Virginians have proved that members of class three unconsciously obey the following law:

In typical Eastern Virginia speech, diphthongal ou or ow is given the dialectal sound represented by (uh-oo) when the diphthong is immediately followed in the same syllable by the sound of a voiceless consonant; but under all other conditions standard ou (ah-oo) is employed.

Examples of words in which dialectal ou is heard are about, couch, doubt, drouth, ${ }^{3}$ house, mouth, ${ }^{2}$ out, pouch, ${ }^{2}$ south. ${ }^{3}$ trout.

Examples of words in which standard ou is heard are: vowel.

(1) bough, brow', cow, dower, dowry, drowsy, how', trowel, wow,

(2) abound, account, droan, foul, growl, loud, mountain, proud, prowel, sound.

Tests indicate that the large majority of Eastern Virginians belong to class three. but there are members of class two on the Virginia Peninsula - notably in James City County-and elsewhere in the state. These regularly sound dialectal ou in all the groups of words of which examples are given in the above lists.

The second of the two distinctive and yet largely neglected sounds in the speech of Eastern Virginians is that of $i$ in such words as bright, like, and price. The standard sound of this diphthong is approximately that of $a$ as in father plus that of $i$ as in pin; the dialectal sound is approximately that of $u$ as in hut plus that of $i$ as in pin. The standard sound may be indicated by $(a i)$ or $\left(a l_{l}-i\right)$; the dialectal by $(u / h-i)$.

1 The few references to dialectal ox that can be found are of some interest. See H. C Wyld, History of Modem Colloquial Engtish. New York. 1920, pp. 230-232; the Nex Stardard Dictionery, New York, 1913, p. XXVII; and Sylvester Primer, "The Pronunciation of Fredericlebure. Virginia," in the Publications of the Modern Languege Association of Americe, V, 198 ff.

$2 C h$ is a voiceless consonantal digraph.

$3 T h$ is in this word a voiceless cousonantal digraph. 
Though this pronunciation or one very much like it is mentioned by several writers, ${ }^{1}$ no suggestion of the real distinction made by Eastern Virginians in the use of standard and of dialectal $i$ can be found. That distinction may be expressed in the following law:

In typical Eastern Virginia speech, diphthongal $i$ is given the dialectal sound represented by (uh-i) under two conditions: (1) when the diphthong is immediately follooced in the same syllable by the sound of a voiceless consonant; and (2) when the diphthong occurs at the end of a syillable which is immediately followed in the same word by an unaccented syllable beginning with the sound of a voiceless consonant and containing an obscurely pronounced vowel.

Examples of words pronounced with dialectal $i$ are:

(1) advice, appetite, bite, fight, ice, knife, life, sitc, white, wife.

(2) cipher, hyphen, hypodermic, license, niter, nitrogen, rifle. stifle, viper, vital.

Examples of words pronounced with standard $i$ are :

(1) alibi, miplify, fly, high, lie, nigh, pry, sigh, vie, why.

(2) bias, buyer, dialect, dialogue, diet, hyacinth, myopia, pliant, violet, Zion.

(3) advisory, bridle, final, finality, hilarious, idle, ivy, private, spider, tiger.

(4) biceps, citation, Hyperion, hypotenuse, Isocrates, licentiate, licentious, nitrogenous, typhoid, vitality.

(5) advise, archives, blind, climb, file, hide, kind, lives, time, wives.

It is easy to prove the existence in Eastern Virginia speech-and in that of a few other sections of the country- of the two peculiarities discussed in these pages, but it is somewhat difficult to give a satisfactory explanation of the very positive and regular influence exerted upon the diphthongs ou and $i$ by voiceless consonants. It is certain that this explanation is not etymological. ${ }^{3}$ The present writer is inclined to ascribe the survival of these pronunciations to the fact that an easy mode of speech is very slow to give place to one which calls for more effort and which at the same time results in a combination of sounds rather widely different from one another and therefore sharply contrasted and possibly somewhat harsh when pronounced. It may not be altogether fanciful, then, to conclude that dialectal ou and $i$ are retained in Eastern Virginia speech because they unite more readily and pleasantly with

1 See H. C Wyld, op. cit, p. 224; O. F. Emerson, The History of the English Language, New York 1894, p. 201: Webste's New International Dictionary, p. IfI; and the New Stand. ard Dictionary, p. XXViI.

2 Such a word as nitrote, thongh $a$ is not obscure is pronounced dialectally, possibly becanse the presence of $r$ before a leaves voiceleas $t$ free to infloence :

3 See O. E. Emerson, op. cit., pp. 204206. 
voiceless sounds than do the standard diphthongs of which the so-called "open-throat" vowel ( $a$ as in father) is the first component. But, possibly because the standard diphthongs combine easily with the rather vigorously pronounced voiced consonants, the typical Eastern Virginian has, through the influence of the law of analogy, adopted the regular American pronunciation of all words in ou and $i$ in which the diphthong is not subject to the restraining influence of a voiceless consonant.

There are perhaps no other sounds in the language more frequently confused or interchanged, or about which more irregularity prevails than the sound of 00 as it is heard in boot and the sound of $u$ in use. Even so short a list as that which follows contains words in the pronunciation of which there is a great difference of usage if not of opinion: rule, duke, tune, costume, assume, dune, nude, subdiued, renewed, lute, flute, mute.

If the dictionaries may be trusted in this matter, the pronunciation of $u$ in words of the type given in this list is that of $u$ in use when the vowel is preceded by $b, d, f, g, h, k, l, m, n, p, s, t, t h, v$, or $z^{10}$

In actual practice, however, the speaker whose usage conforms to this rule is exceptional. This can be demonstrated quickly if the reader will ask some of his acquaintances to read aloud the following list, without stating in advance the purpose of the request: beauty, accuse, duty, fume, gewgare, hue. louman, lute, mute, new, purity, assume, costume, tune, enthusiasm, view, zumatic.

The following words of the list may be disregarded, for in them speakers of all ranks and conditions in the United States regularly pronounce $u$ as it is sounded in naming the vowel: beauty, accuse, fume, gewgaw, hue, human, mute, purity, view. But in the case of duty, lute, new, assume, tune and enthusiasm usage is by no means uniform. ${ }^{11}$

Many speakers in the North and the West regularly pronounce $u$ like 00 as in boot in these six words. This tendency is not at all common in the South, where duty, new, and tune would each be given the iu sound in the speech of all classes. Scattered exceptions to this as to almost any other language practice may be found, but they do not invalidate the rule. The group of words represented above by lute, assume, enthusiasm, and zumatic is one of great interest. The prevailing practice in America at large is to sound the $u$ like $o o$ in these words, but the dictionaries regularly sanction the iu pronunciation, which is heard in the speech of a good many careful speakers. This pronunciation, being hardly known to the average speaker and not at all used by him, must be classed as decidedly academic. Certainly it is so in Virginia, where not only the masses of the population but even the majority of cultivated speakers employ the oo sound in these words.

1 Minor differences of vowel sound due to accent are aside from the sabject of this stody and will therefore be disregarded.

2 In the remainder of this discrision the socund of $x$ in wse will be indicated by ix. 
Some words belonging under one or another of the above heads present special difficulty to the student of speech habits because they are pronounced in a way that seems to baffle explanation. The usual pronunciation of $u$ in words like dew and others in which the preceding consonant is $d$ is $u$, but tests indicate that many speakers who say diu when pronouncing dew also pronounce dude as if it were spelled dood. If it is argued that the second $d$ in the word causes the difference, it can on the other hand be pointed out that those Virginians who say dood pronounce the same combination of letters diud in the words subdued, bedewed, and endued.

The true explanation of this singularity of pronunciation may be that the second syllable of subdued, bedererd. and endued is pronounced diud through the influence of the infinitive forms ending in due or dew, the Virginia pronunciation of which is diu. But when a speaker says $d u d \varepsilon$ there is no idea of due or dew in his mind; in other words, no basis for the operation of the law of analogy; and so he avoids the somewhat difficult and awkward combination of sounds made by placing $i u$ between two $d$ 's and says dood. It has been suggested that the oo sound in dude may be due to-the Northern origin of the word; but it seems unlikely that the Southerner would imitate Northern pronunciation more readily in this respect than in others.

Virginians usually avoid the oo sound after $n$, and yet nood is heard as a Virginia pronunciation of nude. This seems all the more inconsistent when it is remembered that the same speakers who say nood pronounce renewed with a $i u$ sound; but the explanation may lie in the fact that the regular pronunciation of the vowel of the infinitive renew is iu. The same analogical tendency mentioned in the case of dude seems to operate here also. In no other way does it seem possible to account for these inconsistencies of pronunciation.

Transpose $n$ and $d$ in nude and the resulting word is $d u n e$, the pronunciation of which in Virginia is doon. This may be accounted for on the same basis mentioned in connection with dude and nude. These pronunciations indicate that the average speaker finds it easier to pass from an $n$ to a $d$ sound, or vice versa, through the medium of oo than through the medium of $u$; but when $u$ is preceded by either $d$ or $n$ and followed by neither of these letters, a clear iu sound is the rule of Virginia speech.

The words flute, blue, slew, flew represent a class of words in which $u$ is preceded not merely by $l$ but by a double consonant, $f l, b l$; sl. Floot, bloo, sloo, floo are the regular Virginia pronunciations, but the dictionaries might naturally be expected to express a preference for the iu sound. This is, however, not the case, the reason for the prevalence of the oo sound being that iu is somewhat more difficult to say after $l$ preceded by another consonant than after $l$ alone.

There is a very widespread tendency among speakers of English to do what is commonly known as dropping $g$ 's. The practice indicated in this phrase is really the substitution of a pure $n$ sound for the combi- 
nation $n g$ as sounded in such words as sing. One does not, however, hear sing called sin or bring brin. In most cases this corruption occurs in the ending of the present participle of verbs, the result being such forms as goin', comin', singin', bringin'. It is also heard in somethin' and nothin', but perhaps never, in Virginia at least, in the pronunciation of anything, in which a clear $n g$ sound regularly occurs. Indeed, this very general peculiarity is almost altogether associated in this state. and doubtless elsewhere, with unaccented syllables. The second syllable of anything is stressed decidedly more than is that of something or of nothing. Hence the proper pronunciation of anytling side by side with somethin' and nothin'.

The substitution of $n$ for $n g$ in unaccented syllables pervades almost all levels of speech in Virginia. The same speaker who carefully avoids the $n$ pronunciation in formal speech may use it habitually in ordinary conversation; and on account of this double standard one should not be surprised to hear in the same sentence, either in formal or informal speech, some $n$ endings thrust in among perfectly faultless $n g$ sounds.

If those persons who have difficulty in avoiding the substitution of $n$ for $n q$ in unaccented syllables have high respect for authority in matters of English usage, they will be interested and comforted to know that at least one English fexicographer has sanctioned the practice. Walker, in his "Hints for Improvement in the Art of Reading," published in 1783, laid down rules to govern this matter which have no force today, if indeed they ever had any; but they are important as showing the existence of the $n$ pronunciation in that day. The substance of Walker's apparently artificial rule was that, since it is always unpleasant to repeat a syllable, such words as bring, ring, sing and others ending in $n g$ should have for the ending of the present participle in instead of ing, giving the forms bringin, singin, ringin. In words like grin it is, according to Walker, desirable to add ing instead of in to avoid the juxtaposition of two in syllables. But modern ears are so accustomed to such forms as bringing, ringing, and singing, ar.d the dropping of $g^{\prime} s$ is so very general. that Walker's law cannot be said to exert any influence on present-day speech.

One of the surest marks of Southern speech is the way or ways in which the letter $r$ is pronounced. Under some conditions this consonant is neglected altogether; under others it is vocalized. One may hear a Southerner pronounce ring. arrant, great, and a good many other words without detecting his nativity, but if he has occasion to use the words far, war, door, morc, it will be seen that the $r$ of each of these terms is given little or no consideration.

A Virginian may try to reform his pronunciation of certain words involving some of the sounds already discussed, but he is almost sure to be entirely satisfied with his treatment of $r$. Southern usage in the matter is not so easy to define and explain as it might seem to be. Anyone accustomed to the use of $r$ according to the speech habits of the North and the West would find it very difficult to mark on a printed page 
the $r$ 's that a Virginian would omit altogether in pronunciation, those that he would vocalize, and those that he would pronounce as would a speaker in another part of the country. It is also true that the typical Virginian himseif, though he never has to stop to think about his $r$ 's in order to pronounce them in the accepted Southern fashion, could not give offhand a clear statement of his usage in this matter.

Final $r$ will be considered first. An outsider, after castally observing Virginia speech. might say that $r$ is habitually dropped at the ends of words; but such is not the case. Of the four words mentioned above, $r$ would regularly be dropped in pronouncing far and war: but in door and more it would be regarded as a vowel. Do-ah or do-uh and mo-ah or mo-uh indicate fairly well the prevailing Virginia pronunciations of these two words. To summarize Virginia usage in connection with final $r$, the following statement is given:

In the usage of many, probably most, Virginians, final $r$, when immediately preceded by the sound of a as in father, the sound of $e$ as in her, the sound of $o$ as in or, or the sound of $i$ or $u$ as in fir. fur, is not sounded at all. When immediately preceded by any other vowel sound, final $r$ is zocalizrd and pronounced in a way approaching the sound of $u$ in hut (indicatcd in this study by uh.)

$R$ in such a word as orc is regarded as final because the following $e$ is silent. In Virginia speech or $c$ and oar are both pronounced $o-u h$.

When $r$ is in any other position than at the end of a word. the following usage prevails:

Initial or medial $r$ immediately followed by a vowel sound, whether the voriel is in the saine syllable with $r$ or in the next syllable following, is given its full or stondard consonant value.

Initial or medial $r$ immediately followed by a consonant loses its consomantal character, becoming silent if preceded by any of the vowel sounds occurring in the acord's car, her, for, fir. fur, but becoming wocal (aith the uh sound) if preceded by any other vowel sound.

Accordingly, $r$ is given its full consonantal sound in Virginia speech in such words as rain. great, forest, and gencration; it is silent in words of the type of harm, term, firm, form, churn; and it has the sound of $u$ in hut $(u h)$, but unstressed, in scarce, fear, fire, course, and similar words.

In many words containing $r$ preceded by long 0 , in which careful speakers in Virginia give $r$ the sound indicated by $u h$, those who are less particular drop it altogether. Examples are $p o^{\prime} c h, d o^{\prime}$, fo'teen for porch, door, fourteen, or, rather. for po-uhch, do-uh, fo-uhteen of cultivated and careful Virginia speech.

Thus far in the discussion of $r$ in Virginia speech the unit of influence has been the word; but it sometimes happens that final $r$, when the next word following begins with a vowel, is influenced by that vowel in such a way as to be given its regular consonantal value. Some speakers 
sound final $r$, as a result of this influence, in such expressions as far oway, where is, where are, poor old John, and others.

Some speakers have difficulty in sounding $r$ under any circumstances; but as this general slighting of the consonant regardless of its position and surroundings is limited to individuals in the country at large rather than to any homogeneous group of speakers in a particular state or section, no special account of it will be taken in this study.

There seems to be a growing tendency in the North and possibly also in the West to pronounce like the first syllable of auditory and like the word azve the letter $o$ before $r$ in accented syllables; that is, in such words as glory, story, more, floor, door, and oral; but Virginians as a rule retain the earlier usage and give the vowel $o$ in these words the same sound that it has in pronouncing the name of the letter itself. Professor G. P. Krapp's statement in his valuable work. The Pronunciation of Standard English in America (page 88), that the only current pronunciations of door and floor are with the azw or au sound certainly does not apply to Virginia speech or to that of the South in general.

In the pronunciation of many speakers, the $o$ sound of words of the type of moral is identical with that of mortal and similar words; but in typical Virginia pronunciation a clear distinction is made. Speakers who make no distinction use the aw sound in both groups of words; but Virginians pronounce the $o$ of moral like that of hot, using the $a w$ sound with the second or mortal group. The Virginia usage is easily reducible to rule and, in fact, is in accord with the principle set forth in the New International Dictionary, section 203 of "A Guide to Pronunciation." The statement there is that the are sound is for the most part limited to "accented syllables with the $r$ not followed by a vowel or another $r$ in the same word, except in the case of inflected verbs ... and the cognate nouns in -er."

Two other sounds in the employment of which there is lack of uniformity in America are represented by the words pool and prill. The words in which these sounds vary are not very numerous. Professor Krapp in his work just cited mentions aloof, butcher, boot, broom, coop, Cooper, food, groom, hoof, hoop, Hooper, nook, proof, rood, roof, rook, room, rooster, root, soon, soot, spook, spoon, woof.

It is believed that the following words of this group regularly have the sound of oo in pool in Virginia : aloof, boot, groom. proof, rood, rooster, root, soon, spook, spoon and woof: the following as regularly have the sound of $u$ in pull: butcher, coop, Cooper, hoop. Hooper, nook, rook; and the rest vary with different speakers: broom. hoof, room.

Another interesting group of words is that represented in the New International Dictionary by soft, off, oft, often, cost, cross, gone, song, long. broth. and clotle. A pronunciation approaching that of aze or au prevails in Virginia for all these words except song and long. In these and others in which $o$ is followed by $n g$ the vowel sound of hot is still 
so generally heard that it may still be regarded as the typical pronunciation of educated Virginians.

Virginians share the general lack of uniformity in pronouncing words of the type of God, log, and fog. Though the aw or au sound, or an approach to it. is of ten noticed, many, if not most, Virginians use the short 0 sound (as in hot) in these three words; but the pronunciation of $d o g$ rather imperfectly represented by dazerg is so common that the pronunciation with short $o$ sounds affected and unnatural to most native ears.

Going, when unstressed, and followed by to, is in rapid or careless speech pronounced goon ( 00 as in wool). Comb and home suffer a similar change at times, becoming coom and hoom (oo as in wool).

Your and poor often become yo-uh and po-uh. In the speech of some careless or illiterate persons the final syllable disappears entirely, leaving $y o^{\prime}$ and $p o^{\prime}$, both of which rime with go.

Upon and from even educated speakers sometimes pronounce upun and frum.

Perfectly familiar to Virginia ears is the pronunciation of join, joist, oil, and similar words with $i$ as in line or light instead of the standard $o i$ sound. The $i$ pronunciation has of course no standing in educated speech in Virginia, but in the seventeenth and eighteenth centuries it was standard and occurred frequently and regularly in the heroic couplets of Dryden and of Pope. where the rimes indicate the pronunciation. Those who use the $i$ sound in these words make the same distinction between the $i$ of join (jine) and that of joist ( $j$ 'ist) as is made in standard Virginia speech between line and light. Jah-in and $j u h-i s t$ would be heard regularly, just as lah-in and luh-ight are in cultivated speech.

The omission of the $h$ sound in words like white and where is not characteristic of the Virginia dialect except in the one word why, and not in this one except when it is used with exclamatory or expletive force. The Virginian would pronounce why in Why did he go? in a way to please the most fastidious; but the same speaker would be likely to say $W^{\prime} y, J o h n$ ! and even, to give force to the question, $W^{\prime} y$, why?

According to Professor Lounsbury, heir. honest, honor, and hour. with their derivatives, are the only words in English in which the initial $h$ is never pronounced. The New International Dictionary gives four words beginning with $h$ that present cases of divided usage. These are herb. hostler, humble, and humor. The three of these most common in Virginia conversation are herb, humble, and loumor; and the great majority of speakers seem still to omit the $h$ in all three. though there are of course careful speakers who follow the modern tendency to insert the $h$ sound.

Another class of dialectal expressions is that in which there is a shift from the sound of one vowel to that of another. Git for get is illiterate English in Virginia as elsewhere. One also hears pin for pen 
and min for men; but more widespread is the pronunciation of what and was as if they were spelled whut and ruz. Not only are both of these pronunciations, whut and wuz, heard in Virginia, but their use is by no means limited to the lower levels of speech. The fact that a speaker says whut is not in itself proof, though it is evidence, that he says arus. In the sentence, What was it? four combinations are possible:

\section{What was it? \\ What wuz it? \\ What was it? \\ What wuz it?}

It is perhaps true that the majority of Virginia speakers who change the vowel in one of these words change that in the other also; and any one who quietly tests the pronunciation of his Virginia friends as to these two words will doubtless be surprised at the small number of those who pronounce both words in the manner indicated in the dictionaries.

The common Southern pronunciation of negro, which is nigrult ( $i$ being sounded as in pin) is all but universal in Virginia. This pronuncation is probably due to the influence of the form nigger, which, besides being a popular substitute for megro, is used in other senses as well.

Some Virginians have trouble with these words: great, say, snake, make, naked, the resulting dialectal pronunciations being smeck. meck, gret, seh (with the $e$ sound heard in set), necked, but the last of these is more widespread in all classes of speakers than any of the others.

Still other cases of vowel shifting sometimes occur in the pronunciation of such words as ear, fear, and sincere, in which the sound of $e$ as in meat gives place to the sound of the same letter in met.

Courage is by careless speakers sometimes pronounced almost as if it were kerridge.

Ketch is a widely used substitute for catch in familiar and illiterate speech in Virginia. Richard Grant White believed that ketch was the general pronunciation of the word in England in the sixteenth and seventeenth centuries. In Middle English times there existed a Midland dialect form cache $(n)$ and a Southern dialect form $k e c c h e(n)$. Catch is of course the standard form today, but the pronunciation ketch seems to be firmly rooted in the speech of a large number of Virginians and other Americans.

So-called short $i$ is slighted in some words. Examples are Latin and Martin, the prevailing Virginia pronunciations of which are Lat'n and Mart'n.

In words like California, Virginia, Lilian, Virginians pronounce $i-w h$ as if it were yuh. Each of these words is therefore a syllable shorter than in standard pronunciation.

Certain pronunciations more or less current in Virginia seem to be due to economy of effort on the part of speakers. Open, something, 
happen, seven, eleven, often become op' $m$, sump' $m$, happ' $m$, seb' $m$, eleb' $m$ (or leb' $m$ ). These dialectal forms do not represent the best Virginia speech, but it would be unfair to say that they are heard only in the conversation of the illiterate. Indeed, some whose speech habits are in the main above reproach are guilty of some of these substitute pronunciations.

In the Old Dominion the $r$ of formard is sometimes slighted and the word is pronounced to rime with Howard and coverd. This pronunciation may have resulted by analogy from these two words and from froward, which was formerly pronounced so that it rimed with Howard and coward.

Of $e r$, ir, or and $u r$ in words like verse, first, worst, prerse, several different pronunciations are noticed. Some speakers sound the $r$, and others omit it; but a third set of speakers pronounce these words with a sound approaching that of $o i$. The last-named pronunciation is common in New York and, in a slightly modified form, in some Southern states; but it is exceptional in Virginia, where the prevailing pronunciation is that in which $e$ is given the standard sound (see any dictionary) and $r$ is not sounded at all.

In Virginia zealnut is sometimes heard with silent $l$. A rather general pronunciation of solder is without an $l$ sound, and this consonant is of course silent in psalm and calm. Moreover, the following words were all pronounced without an $l$ sound in Elizabethan days: altar, halter, psalter, realm, fault, falcon, assault. Since after, according to Ellis, was pronounced auter in the sixteenth century, the following lines of the Fool ing King Lear (I, iv. 340-344) contain perfect rimes:

\section{"A fox, when one has caught her, \\ And such a daughter, \\ Should sure to the slaughter, \\ If my cap would buy a haiter, \\ So the fool follows after."}

Walnut is evidently a survival-and a rare one-of this earlier tendency to omit $l$.

An interesting group of words is that to which fair, hair, pair, pare, pear, scare and lair belong. Virginians usually employ here the sound of $a$ as in man, which may be represented by ae. (The sound is the same heard in Coedmon). In Virginia speech the $r$ is vocalized with the sound indicated by $u /$. The pronunciation of the above words in Virginia is approximately as follows: fae-uh, hae-uh, pae-uh, scae-uh and lae-uh. This pronunciation is interesting for two reasons. In the first place, it is not established as the uniform American pronunciation; and secondly, it is traceable to seventeenth-century British pronunciation. A rather widespread pronunciation, though there is some lack of uniformity for the country at large, may be represented fairly well by fay-er, hay-er, pay-er, scay-er, etc.; but the Virginia usage indicated above can be found in the respelling for pronunciation of a number of words in the list of seventeenth-century pronunciations given in chapter three of the present work. 
Two distinct pronunciations of words ending in unaccented ture are heard in Virginia and doubtless elsewhere. The common practice is to give this final syllable the sound that might be indicated in dialect writing by chuh, especially in polysyllables; but in the word literature, possibly, as is sometimes suggested, by reason of the academic, or at least cultivated, associations of the term, the pronunciation involving a pure $t$ sound, the $u$ of $u s e$ and, in Virginia, vocal $r(u h)$ is often heard. There is no good reason, however, why the chush sound should not be used in literature as well as in furniture, architecture, manufacture, and others.

Words ending in an o sound, such as mellow, fellow, tomato, are heard in Virginia with the o obscured so that the sound of the word is almost that of fell-uh, tomat-uh, mell-uh. Tomah-tuh is a very general Virginia pronunciation.

All but careful speakers in Virginia, and probably throughout the South, pronounce wish so that it rimes perfectly with push and bush. The standard pronunciation rimes with dish and fish. The dialectal pronunciation is evidently a survival that has come straight down from the time when the now obsolete variant zursshe was in vogue.

In some paris of the South her is pronounced in a way that closely approaches huh. In standard speech the sound of $e$ indicated in the dictionaries for this word is followed by that of $r$; but in Virginia speech the standard $e$ sound ends the word when it is pronounced with stress. When unstressed, the word becomes $u h$. Thus, Tell her to come might be represented in dialect by Telluh to come.

The use of $t l$ for $c l$ or $k l$, as in the word clock, has been heard from the lips of educated Virginia speakers, but it is not by any means the prevailing pronunciation in the state.

Dialectal English sometimes takes the form of misplaced accents. A very general Southern pronunciation among all classes of speakers is that of the word idea with the accent on the first syllable. Less general, perhaps, is the still rather commonly heard pronunciation of positively with both the first and the third syllable stressed.

The words yes and no have many pronunciations and substitutes. Affirmation may be expressed in the Virginia dialect by yaes ( $a$ as in man), yeh-uh ( $e$ as in men) yep and yeh, as well as by the standard yes. $M$ - hm is also heard. The corresponding negative forms are, besides no, $n u h$ ( $u$ as in hut, but somewhat nasalized) and neh-o ( $e$ as in men), and one or two sounds approaching that of $m$.

Those readers who have had the patience to follow this attempt to set forth the chief characteristics of Virginia speech may have received the impression that English usage in that state is hopelessly old-fashioned and provincial. But investigation will hardly confirm this judgment, for the standard according to which it is reached is more theoreti$\mathrm{cal}$ than actual, and the language peculiarities of Virginia, which are perhaps not more numerous than those of the North and West, rest in most cases upon as firm and reasonable a foundation as do those of any other American dialect. 
CHAPTER V.

\section{VIRGINIA PRONUNCIATION IN LITERATURE}

Novelists and short story writers of the present time not only make their characters talk, but try to make them talk naturally. The first step in this direction is the employment of a familiar style. Exclamatory expressions and generally accepted contractions are frequently used. Sentences are loosely constructed. and are sometimes purely fragmentary. Stilted, artificial diction is carefully avoided, and colloquial terms are freely introduced.

But these devices, though they give to characters of fiction the appearance of reality, do not constitute dialect writing. In order to rank as a writer of dialect. an author must record something more than widely used colloquialisms. He must set before the reader distinctive or non-standard words and pronunciations that have little or no relish of convention in them, at least in national speech circles.

Even a casual observer is probably impressed by the inconsistency of most dialect writers. A particular speaker's pronunciation of a word is given sometimes in one way, sometimes in another. It is to be expected that writers will differ in their representation of a speech peculiarity, but frequently the same author indicates a dialectal form in more than one way. It must be remembered, however, that in real life consistency in language is by no means universal. Though the speech habits of an individual are not al together without regularity, they are materially affected by even a slight change in the conditions of speech. It will not be surprising, then, to find a mixture of dialectal and standard forms in almost any example of dialect writing to which the reader may turn.

Moreover, a writer, either from carelessness or design, often uses a good many standard forms that a true and natural speaker of dialect would hardly employ. When consciously indulged in, this practice is probably due to the belief that all the advantages and effects of dialect writing can be secured without rigid adherence to non-standard forms, and to the fear that the reader will be repelled by too radical and thoroughgoing a departure from normal speech.

It appears also that authors, in recording dialect. seek not only to spell words in a way to suggest the dialectal pronunciation, but to preserve a sufficient resemblance to the correct forms to make it easy for the reader to see at once what standard words the dialectal spellings represent. A writer cannot afford to mutilate a word beyond easy recognition, for the average man does not read a dialect story as an exercise in language.

In view of these characteristics of dialect writing, it follows that literature alone does not furnish sufficient and altogether trustworthy material for a detailed study of the speech customs and peculiarities of a people. The living language, caught from the lips of speakers who are totally unaware of the fact that their accents are being noted, is the one 
best guide. But the efforts of writers-to all of whom the story as 2 whole, not the dialect, is of chief importance-are useful for supplementing other methods of approach. Hence the introduction at this point of several short studies of representative passages in the Virginia dialect.

To George W. Bagby's interesting volume of prose writings, The Old Virginia Gentleman and Other Sketches, the late Thomas Nelson Page has contributed an appreciative introduction. To this introduction and to the sketches themselves those readers are referred who wish to see a reflection of the Virginia of yesterday. The selection from Bagby chosen to illustrate his writing in dialect is found in the delightfully humorous essay, "Bacon and Greens."1 The passage reads as follows:

In person, the old man is above the medium height, "dark-complexioned," spare built and generally long and lean in the lower limbs, - and that's the reason he rides a horse so well. His voice is loud, owing to a habit he has of conversing familiarly with the hands in the field about a mile and a half off. His vision is wonderfully acute-partly from long practice with the rifie, and partly from the custom of inspecting his neighbors' vehicles at incredible distances. If he live on the side of the road, you will see him on Sunday eying a cloud of dust on the remote horizon. "Jeems," he will say to his son: "Jeems, ain't that old Peter Foster's carryall?" "Yes," says Jeems, without a moment's hesitation; "and I'll be dad-shim'd if that off mule has been shod yit." His accent is as broed as the nose of his blackest negro. He says "thar" and "whar," "upstars" and "down in the parster," and talks about "keepin' a appintment," not next year, but "another year," when he expects to raise "a fine chance of curcumbers" in the "gearden," and 2 "tollibly far crap o" tubbarker." If he is a tidewater man, he does not say "chance." but "charnce," and instead of saying the "har" of the head, he says "heyar." If he eats cornfield peas much, he becomes a virulent Virginian, and caps the climax of bad English by some such expression as "me and him was a-gwine a-fishin." This he does, not for the lack of knowiledge, but partly becanse he loves to talk as unlike a Yankee as possible, partly because he "don' keer" particularly about his language or anything else except his political and religious opinions, and mainly because he is entirely satisfied (as, indeed, all Virginians are) that the English is spoken in its purity nowhere on this earth but in Virginia. "Tharfo" he "kin affode" to talk "jest" as he "blame chooses."

The part of the quoted paragraph dealing with dialect should be read carefully, for every non-standard form rings true. This does not mean that every Virginian says tharfo', kin, affode, etc., nor does it mean that any considerable number of educated Virginians today use these pronunciations. But that they do prevail among careless and uneducated speakers of the state is indicated by the fact that they have a by no means unfamiliar sound to Virginia ears. The distinctive characteristic of this dialect writing is that it is the resuit of a conscious and very successful attempt on the part of the author to include in a small space a goodly number of current divergences from standard English. In the passage quoted will be found, therefore, an interesting, if extreme, picture of a part of the Virginia dialect at its best-or worst.

Thomas Nelson Page, an acknowledged master of the negro dialect spoken in Virginia, has introduced several white characters with interest-

1 The Old Virginic Gentleman and other Sketches, pp. 55-57. Used by permission of the peblishers, Charles Scriber's Sons. 
ing and typical speech peculiarities in On Newfound River. In the Preface the author says:

"The reader will, perhaps, bear in mind that 'On Newfound River' does not pretend to be a Nowel; but is on its face a 'story' $a$ Love-story if you will - of simple Country Life in Old Virginia. The 'setting' is wholly that of the Country, the surroundings are all those of a life far from cities, the incidents are, for the most part, those little commonplace events which might have taken place in a rural neighborbood before the war, where the gentry ruled in a sort of manorial manner and their poorer neighbors bore a relation to them part retainer, part friend"

It is from the conversation of some of these "poorer neighbors" that the following paragraphs in dialect are quoted : 1

"Yes, an' Pokeberry," said Mills, taking up the thread just where he had left off. "He pert him an' the squa'r together. He said be won't have him trackin' his niggers with hom's."

"Houn's can't hurt nobody," drawled one of the group. "Houns is the feardest dogs in the worl"."

"Taint that," explained Mills, with superiority. "He says, 'tis the feelin'." fence.

"I wonder the Major ain' never had the squa'r turned out," said a man on the

"Nor; he wouldn't put himself out enough to do that," explained Mills. "He knows the squa's is po,' and he won't take no step to take the office away from him."

"I b'lieve he'd rather keep the squa'r in than to turn him out," suggested Hall, who had some sense of humor. "If he was to los' him, he wouldn' have nobody to abuse."

"He could abuse that tother ole man crost the river yonder where's got his land" said Mills, with a sideways nod of his head to the smoky ridge away across the wooden bottom to the right, through which Newiound crept.

"That's so," assented Hall, cordially. "Wonder what makes the Major d'spise him so? Becus he wouldn' sell him the ole place?"

"Nor; becus he's so curious; becus he won't have nothin' 't all to do with nobody, and jes' keeps himself shet up with them two ole niggers an' that little gal o' his. They say, to be sure, he's mighty good to her-leastways, so the niggers says, and they knows everything."

"The Major says he ain' never been able to lay eyes on him since he come heah an' settle down on that place right crost the river from him, where his fathers was born and raised, and where by rights blongest to him anyhow. He says he shet himself up like a snake in his hole, and he wisht he'd shet his cows up too."

There was a gleam of amusement at the witticism about the cows which was appreciated by the plain farmer folk.

"Ain' never seen him in that time?" repeated one or two. "Does look like something was wrong."

The peculiar flavor of the speech of illiterate Virginians is so delightfully given in the words of Mills and his companions that it seems captious to point out such minor inconsistencies as nothin' (1. 16) and something (1.25), and (1.8) and $a n^{\prime}$ (1.2).

Virginia authors of course do not ordinarily attempt to represent dialectally the speech of any but uneducated characters of the same state, for the usage of educated Virginians, being that of the writers themselves, is naturally regarded by them as standard English. The following selections, setting forth a single monologue by Mrs. Bangs, a typical representative of thriftless poverty, is a good example of Mrs. Roger A. Pryor's dialect writing in The Colonel's Story (pp. 17-19):2

I On Newfonsd Rion, pp. 28, 29. Used by permiacion of the publisbers, Charles Scrib-

2 Used by permisaion of the poblishers, The Mremillan Company. 
Won't Miss Shirley an' Dolly 'light? Wall-I can't blame 'em. Oh, no, sir, the pea-fowl won't skeer yo' horse. He ain't wild. He jus' feel sorter 'shamed an' naked-like 'cause I palled out his tail feathers yistiddy. That's why he's runnin'. No, sir, I ain't sellin' 'em this spring. It's little I've got to set of my front.room. let alone sellin' my pea-fowl feathers. Run in, sister, an' tell Ma'y Jane to sen' out them las' feathers to show little Dally. Thank ye Cunnel!- the meal lasted toler'ble well an' the bacon, too. They jus' about giv'n out now. I wouldn't mine havin' a quarter o' lamb an' a iew pounds $o^{\prime}$ flour:-'twould be a sort $o^{\prime}$ change. Mr. Bates? No, sir,-I ain't see Mr. Bates for a mont' or mo'. You needn' sen' word to him to come aroun'. We can't git along. 'Taint no use for Mr. Bates to come here, settin' and theein' an' thouin' me 'bout bringin' up the chillern industtrus. I want to know what he knows bout chillern! He ain't nuver been down with nine. an' up ergin to do fur 'em; - let alone mumps an' chickep-pox, an' hoopin' cough ar' measles! Hit's mighty easy talkin'. I hear folks say them Quakers nuver speaks onless the sperrit moves 'em. The sperrit cert'nly is spry roun' $\mathrm{Mr}$. Bates when he comes here. Hit nuver moves him to give us nothin'! He ain't give us a cent, nor a peck $0^{\circ}$ meal; jus' sets 'roun' and talks religion. Maybe he thinks he can convert me an' Ma'y Jane to be Quakers; but Ma'y Jane ... say she never could make them box-pleat Quaker crowns-she never could get 'em to set. No, sir, I ain't hear a word from Mr. Bangs. Thar's them as says we fout 'fore he lef' me. Mr. Bangs never strucken me a lick sence I was the mother of six-an' I 'low 'twas my fault then: answerin' of him back when he was wo' out with them chillern. 'Tain't likely he'd wait twel I was the mother o' nine ef he was layin' out for to leave me. No, sir. - we didn't have no words mo'n common. I never did hold with lettin' no man call me ha'sh rames 'thouten me sayin' the same words back at 'im. Ther wornt no onfrennliness - jes' let 'im see how them words soun'. He jus' up and tole me he goin' for a walk, two mont's ago come nex' Sunday, an' he took an' slip out the back do' an' I ain't see him sence. He'll come back befo' frost, I reckon. He never done no work no how in summer-time, 'cept'n huntin' the weasel when he come terrefyin' the chickens. Sence he went away I los' fo' of my forwardes' pullets. I cert'nly was sorry he carried his gun with 'im. The hawks pester me turrible with my young chickens; an' Tom he kin shoot jus' as well as his $\mathrm{Pa}$. Oh, thank ye. Cumnel! Thank ye! Tom'll cert'nly be proud to have a gun! His $\mathrm{Pa}$ needn't hurry home now. Well, you goin? I cert'nly am obleeged to you for callin' by. Good-bye, Miss Shirley! Ask yo' $\mathrm{Pa}$ please to drop by an' see Ma'y Jane. Ask him to bring her a race or two $o^{\prime}$ ginger. She 'pears right down poly an' peaked this spring-don't do nothin' but jus' set an' set; an', oh, Miss Shirley! 'Fo' you git out o' hearin'-ask Miss Prissy to len' me the laan of her sleeve pattern. Ma'y Jane can't get her cornsent to go to meetin' in them skimpy sleeves o' hern an' thar's goin' to be a baptizin' a mont' from nex' Sunday. ....

It will be observed that in the above passage the author has made free use of peculiarities, not only of pronunciation, but of syntax and vocabulary as well. Other noteworthy characteristics of the selection are its naturalness of style and the unusual fullness with which dialect forms are employed. Comparatively few inconsistencies occur.

The Deliverance, by Ellen Glasgow, has among its Virginia characters Sol Peterkin, described by the author as a "low-born white" (p. 9). He is the speaker in the paragraph that follows (p. 7) :1

Peterkin snorted. "Who? Mr. Christopher? Well, he warn't more'n ten years old when his pa went doty an' died, an' I don't reckon he's had much larnin' sence. I've leant on the gate myself an' watched the nigger children traipsin' by to the Yankee woman's school, an' he drivin' the plough when he didn't reach much higher than the handle. He used to be the darndest leetle brat, too, till his sperits got all freezed out o' him. Lord! Lord! thar's such a sight of meanness in this here world that it makes a body b'lieve in Providence whether or na"

1 Used by permission of the pablisbers, Doubleday, Pase and $\mathrm{Ca}$ 
If Peterkin would say more'n he would doubtless say higher' $n$ for higher than. Several standard forms occur for which dialectal expressions might be substituted.

The study of the Virginia dialect in literature might be continued indefinitely; but a sufficient number of passages have been given to indicate its main characteristics. Since Virginia authors seldom attempt to represent dialectally the speech of any but uneducated speakers of that state, it would at first thought seem advisable to include some of the attempted representations of Virginia educated speech by authors from other parts of the country. But the ability to write accurately in a dialect to which one is not thoroughly accustomed through every-day association is so rarely acquired that Southern authors are almost the only Virginia dialect writers whose works are of any value to the student of the speech peculiarities of that state.

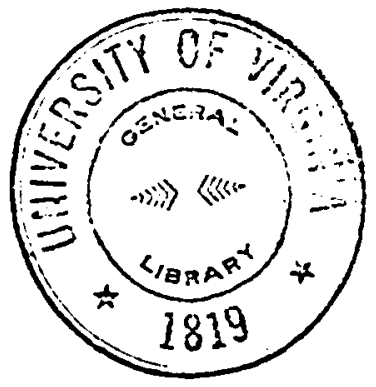


CHAPTER VI.

\section{VIRGINIA PRONUNCIATION AND STANDARD PRONUNCIATION}

\section{A Comparison}

Some idea of the extent to which the Virginia dialect appears in connected speech may be gained from a study of the way a Virginian would read the following paragraphs from the seventh chapter of Dickens's Pickwick Papers. Perhaps no Virginian would use all the non-standard forms here recorded, but they are all heard in the state. The chief words in the quotation that have dialectal variants are briefly discussed in the notes at the end the selection.

"Stand ${ }^{1}$ aside, then. Now for ${ }^{2}$ it."

The boy shouted ${ }^{3}$ and shook ${ }^{4}$ branch ${ }^{5}$ with a nest on ${ }^{6}$ it.

Half a dozen young rooks in violent conversation, flew out ${ }^{7}$ to ask ${ }^{8}$ what ${ }^{9}$ the matter was. ${ }^{10}$ The old ${ }^{11}$ gentleman fired ${ }^{12}$ by way of ${ }^{13}$ reply. Down ${ }^{14}$ fell one bird, ${ }^{15}$ and off ${ }^{16} \mathrm{flew}$ the others. ${ }^{17}$

"Take him ${ }^{18}$ up, Joe," said the old gentleman.

There ${ }^{19}$ was a smile upon ${ }^{20}$ the youth's face as he advanced. Indistinct visions of rook-pie floated through his imagination. He laughed ${ }^{21}$ as he retired 22 with the bird-it was a plump one. away."

"Now ${ }^{23}$ Mr. Winkle," said the host, reloading ${ }^{24}$ his own gun. "Fire ${ }^{25}$

Mr. Winkle advanced, and levelled his gun. Mr. Pickwick and his friends cowered ${ }^{26}$ involuntarily to escape damage from ${ }^{27}$ the heavy fall of rooks which they felt quite ${ }^{28}$ certain ${ }^{29}$ would be occasioned by the devastating barrel of their ${ }^{30}$ friend. There was a solemn pause-a shout -a flapping ${ }^{31}$ of wings-a faint click.

"Hallo!" said the old gentleman.

"Won't it go?" inquired Mr. Pickwick.

"Missed fire,"32 said Mr. Winkle, who was very pale, probably ${ }^{33}$ from disappointment.

"Odd," said the old gentleman, taking ${ }^{34}$ the gun. "Never ${ }^{35}$ knew one of them ${ }^{36}$ miss fire before. ${ }^{37}$. Why, ${ }^{38}$ I don't ${ }^{39}$ see anything ${ }^{40}$ of the cap." Cap!"

"Bless my41 soul," said Mr. Winkle. "I declare42 I forgot ${ }^{43}$ the

The slight ${ }^{44}$ omission was rectified. Mr. Pickwick crouched ${ }^{45}$ again. ${ }^{46}$. Mr. Winkle stepped forward 47 with an air ${ }^{48}$ of determination and resolution; and $\mathrm{Mr}$. Tupman looked out ${ }^{49}$ from behind a tree. The boy shouted; - four ${ }^{50}$ birds flew out. Mr. Winkle fired. There was a scream as of an individual-not a rook-in corporeal anguish. Mr. Tup- 
man had saved the lives of innumerable unoffending birds, by receiving 2 portion ${ }^{51}$ of the charge ${ }^{51}$ in his left arm. $^{51}$

To describe the confusion that ensued ${ }^{52}$ would be impossible. To tell how Mr. Pickwick in the first ${ }^{53}$ transports $^{54}$ of his emotion called Mr. Winkle "Wretch!" how Mr. Tupman lay prostrate on the ground; and how Mr. Winkle knelt horror-stricken ${ }^{55}$ beside him; how Mr. Tupman called distractedly upon some feminine Christian name, and then opened ${ }^{56}$ first $^{53}$ one eye, and then the other, ${ }^{57}$, and then fell back and shut them both;--all this would be as difficult to describe in detail, as it would be to depict the gradual recovering of the unfortunate individual, the binding up his arm with pocket-handkerchiefs, and the conveying him back by slow degrees supported ${ }^{58}$ by the arms of his anxious friends.

They drew near ${ }^{59}$ the house. ${ }^{60}$ The ladies were at the garden-gate, ${ }^{61}$ waiting for their arrival and their breakfast. The spinster aunt ${ }^{62}$ appeared ; $; 3$ she smiled, and beckoned them to walk quicker. 'Twas evident she knew not of the disaster. Poor ${ }^{64}$ thing! There ${ }^{65}$ are $^{66}$ times when ${ }^{67}$ ignorance is bliss indeed. 68

'STAND. - The careless and uneducated often say stan'.

2FOR IT. Some speakers would sound $r$ because of the influence of the $i$ of $i t$; others would say fow it.

${ }^{3}$ SHOUTED. The normal Virginia pronunciation is shuh-ooted.

${ }^{4}$ SHOOK. Shuck is decidedly illiterate.

${ }^{5}$ BRANCH. See p. 22.

${ }^{6} \mathrm{ON}$. Few Virginians sound $o$ in this word as in hot. Awen is a fairly good literal representation of the usual pronunciation of on.

7OUT. Uh-oot is the common pronunciation.

8ASK. See p. 22.

${ }^{9}$ WHAT. Both the standard pronunciation and whut occur. See p. 32.

${ }^{10}$ WAS. The standard pronunciation and zuz are both heard. See p. 32.

11OLD. Only those who say stan' omit the $d$ here.

12FIRED. Fi-uhd is the cultivated pronunciation. Fah-d or fah-uhd are heard on the illiterate level.

${ }^{13} \mathrm{OFF}$. The standard $0 v$ is said by educated speakers, but $u v$ and in some phrases $o^{\prime}(u h)$ are frequently heard careless or illiterate pronunciations. In educated speech the pronunciation of the word when unstressed in the sentence or phrase approaches $u v$, weakened, of course.

14DOWN. Daeown is heard in the speech of many whose language habits are, in the main, good; and it is general among the illiterate.

${ }^{15} \mathrm{BIRD}$. To give the prevailing Virginia pronunciation, give $i$ the sound indicated for this word in the dictionaries and omit $r$ altogether. $B$ and $d$ of course have their standard sounds.

26OFF. Virginians may not take delight in admitting that azof is as close an approach to their pronunciation of off as can be given with the regular alphabet, but such is the case. 
${ }^{17}$ OTHERS. Uthuhs is the only pronunciation generally heard. ${ }^{18}$ HIM. This often becomes 'im when unstressed.

19THERE. Virginians generally say thae-uh.

20UPON. Upun is often heard, even among the educated.

21LAUGHTER. See p. 22, 33.

22RETIRED. Reti-uhd is general.

${ }^{23}$ NOW. Sometimes naeow is heard.

24RELOADING. Careless and illiterate speakers say reload" $n$ '.

25FIRE AWAY. See for it. 2

${ }^{26}$ COWERED. Cow-uhd corresponds to fi-uhd ${ }^{12}$ and reti-uhd 22 above.

${ }^{27}$ FROM. Even when stressed (it is unstressed here) this word is often called frum.

${ }^{28}$ QUITE Typical Virginians regularly say quuh-ite.

${ }^{29}$ CERTAIN. For the sound of er in this word in Virginia, see bird. ${ }^{15}$ The pronupciation of the second syllable is usually that indicated by the spelling cert' $n$.

30THEIR. Vi-ginians generally say thae-uh.

${ }^{31}$ FLAPPING. See reloading. 24

32FIRE. Fi-uh prevails in Virginia

${ }^{33}$ PROBABLY. In rapid, careless, or illiterate speech prob'ly is used.

${ }^{34}$ TAKING. See reloading.24

${ }^{35}$ NEVER. Nev-uh is the Virginia pronunciation.

${ }^{36} \mathrm{ONE}$ OF THEM. This phrase is corrupted at times to such an extent that it becomes one $u v$ ' em or one $u b$ 'em.

${ }^{37} \mathrm{BEFORE}$. The regular pronunciation is befo-uh.

${ }^{38}$ WHY. As an exclamatory word this is $w y$ in Virginia.

${ }^{39}$ DON'T. Though usually pronounced as spelled by Virginians, this contraction is sometimes still further shortened, becoming don' or even $d o^{\prime}$ (long $o$, nasalized rather strongly).

${ }^{40} \mathrm{ANYTHING}$. A rather widespread pronunciation of thing in Virginia is theng.

41MY. In the expression in which the word here occurs it would generally be given its regular pronunciation; but when not emphatic my becomes muh.

42DECLARE. Decloe-uh is the typical Virginia pronunciation:

${ }^{43}$ FORGOT. Virginians usually, or certainly very often, say fuhgot.

4SLIGHT. Sluh-ight is regularly heard in Virginia.

${ }^{45}$ CROUCHED. Cruh-ooched is the typical Virginia pronunciation.

${ }^{46}$ AGAIN. The more careful speakers say agen, but the pronunciation of the second syllable like the verb gain is sometimes heard.

47FORWARD. The standard pronunciation predominates, but fozeord, riming with cowverd, is used by some educated speakers.

${ }^{48}$ AIR. $A e-u h$ represents Virginia usage. 
${ }^{49}$ OUT. Uh-oot is used almost exclusively.

SoFOUR. Fo-uh is the cultivated pronunciation.

SIPORTION, charge, arm, are pronounced po-uhtion, chahge, ahm.

52ENSUED. $U$ would be given the sound of 00 as in pool in all but academic circles in Virginia.

53FIRST. See bird. ${ }^{15}$

54TRANSPORTS. Virginians usually say transpo-uhts.

${ }^{55} \mathrm{HORROR}-\mathrm{STRICKEN}$. The first part of this compound is pronounced horruh ( $O$ as in hot, one $r$ sounded).

${ }^{36}$ OPENED. Very often opemed, or op'md is heard, especially in informal or illiterate speech.

37AND THEN THE OTHER. In this word group, the $d$ of and would be dropped by many educated speakers and by the great majority of speakers of other levels. The word is at times reduced to ' $n$ '.

${ }^{58}$ SUPPORTED. The $r$ is vocalized and the pronunciation is suppouhted; but careless speakers say suppo'ted.

59NEAR. The dialectal pronunciation is neh-uh ( $e$ as in net).

${ }^{60} \mathrm{HOUSE}$. This is regularly huh-oose.

${ }^{61}$ GARDEN-GATE. Those speakers who use the vanishing $y$ sound at all would certainly employ it in the first syllable of garden (gyorden).

${ }^{62}$ AUNT. See p. 22.

${ }^{63}$ APPEARED. This is sometimes pronounced appe-uhd.

${ }_{64}^{6} \mathrm{POOR}$. The standard, or dictionary, pronunciation, and two others, $p o-u h$ and $p \sigma^{\prime}$, are heard, according to the education or language pride of the particular speaker.

${ }^{65}$ THERE ARE. See for it and fore azwy.

${ }^{66} \mathrm{ARE}$. Virginians say $a h$ unless the $r$ is sounded through the influence of a vowel in the next word.

${ }^{67}$ WHEN (hwen). Virginians regularly sound every letter in this word.

68 One or two further comments may be added. The word to, which occurs several times in the selection from Dickens, is sometimes called toe by the careless and the uneducated: and the sound of vocal $r(u h)$, which is characteristic of cultivated speech in several of the above words. is not widely used by the uneducated. Hence the illiterate speaker would say $f o^{\prime}$ instead of fo-uh, transpotes for transpo-uhts, and befo' for befo-uh. He would, however, make use of the uh sound in pronouncing appeared, fired, and near: The tendency to drop medial or final $r$ without substituting anything for it prevails mainly when the letter is preceded by long $o$. Thus illiterates say both fo'ce and fo' (for force and four).

In this discussion attention has been called to a few instances in which the pronunciation of a word is influenced by its position with 
reference to other words. Other examples are as follows: has to (pronounced hass to), have to (pronounced haff to), great deal (pronounced gradle so that it rimes with ladle), and pass your, which tends to become pash your or pash yuh in such sentences as Pass your plate. Hass to and haff to show the tendency of final voiced consonants to become voiceless before a word beginning with a voiceless consonant; graydle indicates that a final voiceless consonant is in danger of being obscured or lost before a word beginning with a voiced consonant; and pash for pass when the word following is your illustrates the same tendency that is exemplified in the pronunciation of such words as confession, passion, and session.

Some words vary in pronunciation with the varying degrees of emphasis desired in different sentences. Offensive and defensive, for examples, are almost certain to be accented on their first syllables when used in the same sentence; and emphatic my, as in This is my book, not yours, differs materially from Hand me muh book, in which ownership it not emphasized.

In the expression at all the stressed word all often attracts $t$ to itself, the result being $a$ tall.

Most of these pronunciations are heard in the speech of all but the most precise Virginians.

\section{CONCLUSION}

If a Virginian should try to normalize his speech according to general usage or to a particular authority, his conversation would then seem as unnatural to others of his own state as it now appears to speakers of the other two general sections of the country; and it will probably be a good many years before the dialectal pronunciations that now prevail fall into disuse through the influence of a theoretical national standard. The attempt in this study has not been to prove that Virginia English is either superior or inferior to that of other states. The aim has been merely to record Virginia usage of the past and of the present. 


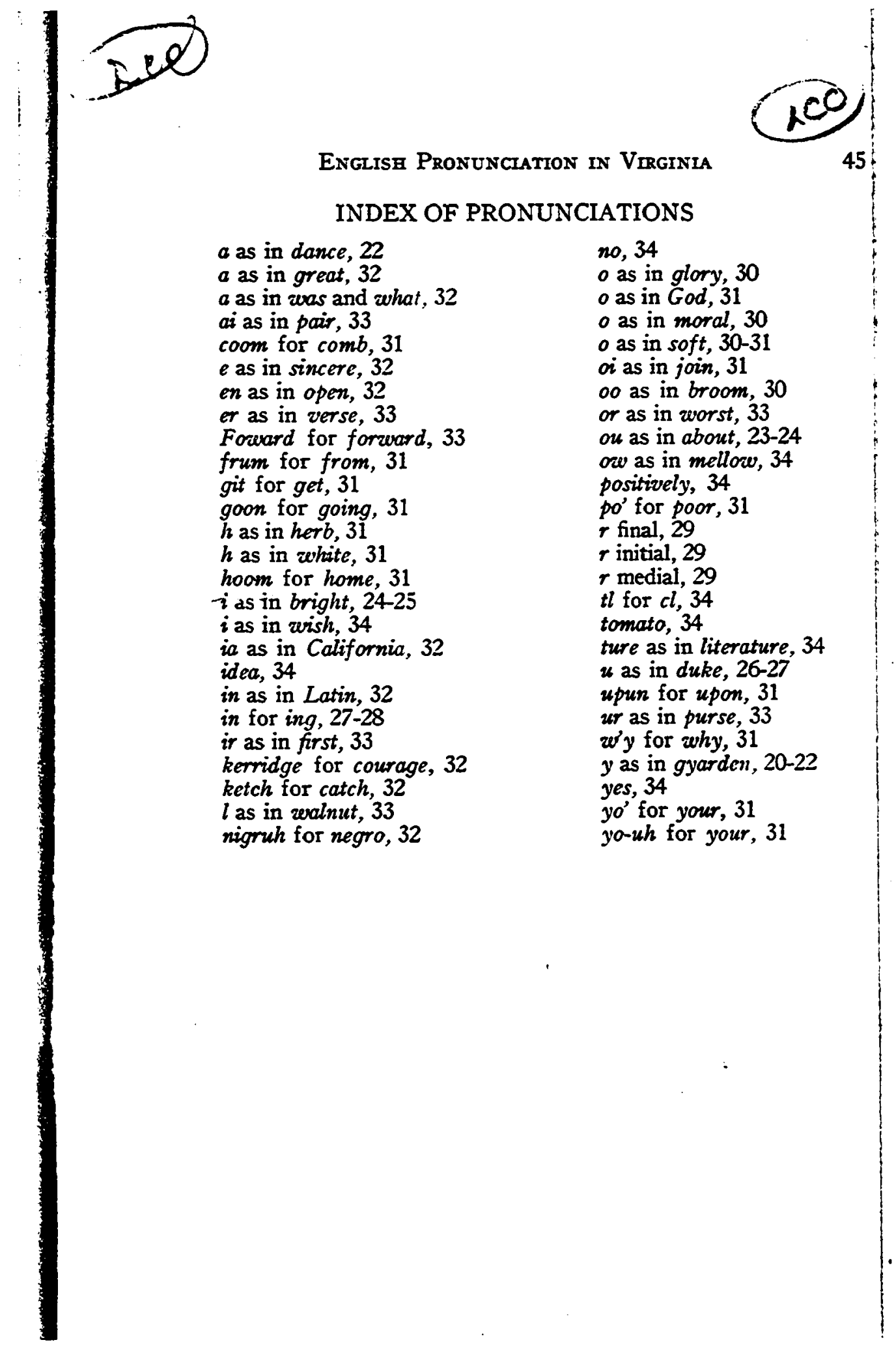

